\title{
Theranosties
}

Review

2014; 4(5):514-533. doi: 10.7150/thno.8137

\section{Bioabsorbable Stent Quo Vadis: A Case for Nano-Theranostics}

\author{
Buket Gundogan ${ }^{1,2^{*}}$, Aaron Tan ${ }^{1,2^{*}}$, Yasmin Farhatnia ${ }^{1}$, Mohammad S. Alavijeh ${ }^{3}$, Zhanfeng Cui ${ }^{4}$, Alexander \\ M. Seifalian ${ }^{1,5 \bowtie}$ \\ 1. Centre for Nanotechnology \& Regenerative Medicine, UCL Division of Surgery \& Interventional Science, University College London, \\ London, UK \\ 2. UCL Medical School, University College London, London, UK \\ 3. Pharmidex Pharmaceutical Services Ltd., London, UK \\ 4. Oxford Centre for Tissue Engineering \& Bioprocessing, Institute of Biomedical Engineering, Department of Engineering Science, Uni- \\ versity of Oxford, Oxford, UK \\ 5. Royal Free London NHS Foundation Trust, London, UK \\ * Both authors contributed equally to this work.
}

$\triangle$ Corresponding author: Alexander M. Seifalian, MSc, PhD, FIoN, FSB, Professor of Nanotechnology \& Regenerative Medicine, University College London. a.seifalian@ucl.ac.uk; +44-207-830-2901

(C) Ivyspring International Publisher. This is an open-access article distributed under the terms of the Creative Commons License (http://creativecommons.org/ licenses/by-nc-nd/3.0/). Reproduction is permitted for personal, noncommercial use, provided that the article is in whole, unmodified, and properly cited.

Received: 2013.II.15; Accepted: 2014.01.28; Published: 20I4.02.22

\begin{abstract}
Percutaneous coronary intervention (PCl) is one of the most commonly performed invasive medical procedures in medicine today. Since the first coronary balloon angioplasty in 1977, interventional cardiology has seen a wide array of developments in PCl. Bare metal stents (BMS) were soon superseded by the revolutionary drug-eluting stents (DES), which aimed to address the issue of restenosis found with BMS. However, evidence began to mount against DES, with late-stent thrombosis (ST) rates being higher than that of BMS. The bioabsorbable stent may be a promising alternative, providing vessel patency and support for the necessary time required and thereafter degrade into safe non-toxic compounds which are reabsorbed by the body. This temporary presence provides no triggers for ST, which is brought about by non-endothelialized stent struts and drug polymers remaining in vivo for extended periods of time. Likewise, nano-theranostics incorporated into a bioabsorbable stent of the future may provide an incredibly valuable single platform offering both therapeutic and diagnostic capabilities. Such a stent may allow delivery of therapeutic particles to specific sites thus keeping potential toxicity to a minimum, improved ease of tracking delivery in vivo by embedding imaging agents, controlled rate of therapy release and protection of the implanted therapy. Indeed, nanocarriers may allow an increased therapeutic index as well as offer novel post-stent implantation imaging and diagnostic methods for atherosclerosis, restenosis and thrombosis. It is envisioned that a nano-theranostic stent may well form the cornerstone of future stent designs in clinical practice.
\end{abstract}

Key words: drug-eluting stent; bioabsorbable stent; theranostics; nanotechnology

\section{Introduction}

Percutaneous coronary intervention (PCI) is currently one of the most commonly performed invasive medical procedures in medicine today[1]. This procedure is indicated in stenotic coronary arteries, which is a manifestation of atherosclerosis (Figure 1)[2]. Since the first coronary balloon angioplasty in 1977[3], there has been an ever-growing plethora of developments and advancements which have led to 
the field of interventional cardiology that we see today[1]. With the implantation of the first expanding coronary stent reported in 1986[4], otherwise known as the bare metal stent (BMS) it was quickly established soon after that patency rates were considerably increased with the use of coronary stents in angioplasty[5]. In contrast to balloon angioplasty, coronary stents prevent exceeded distension of the vessel which may contribute to aneurysm formation[6]. By 1999, coronary stents were implanted in $84.2 \%$ of PCI oper- ations[7]. However, in spite of the obvious successes of these new stents over balloon angioplasty, problems emerged in the form of neointimal hyperplasia, which affected $15 \%$ to $30 \%$ of patients[6, 8-12]. Neointimal hyperplasia is an inflammatory response to the foreign material of the stent, whereby a whole host of inflammatory mediators are upregulated to cause the proliferation of vascular smooth muscle cells which ultimately culminates in the restenosis of the vessel lumen[11].

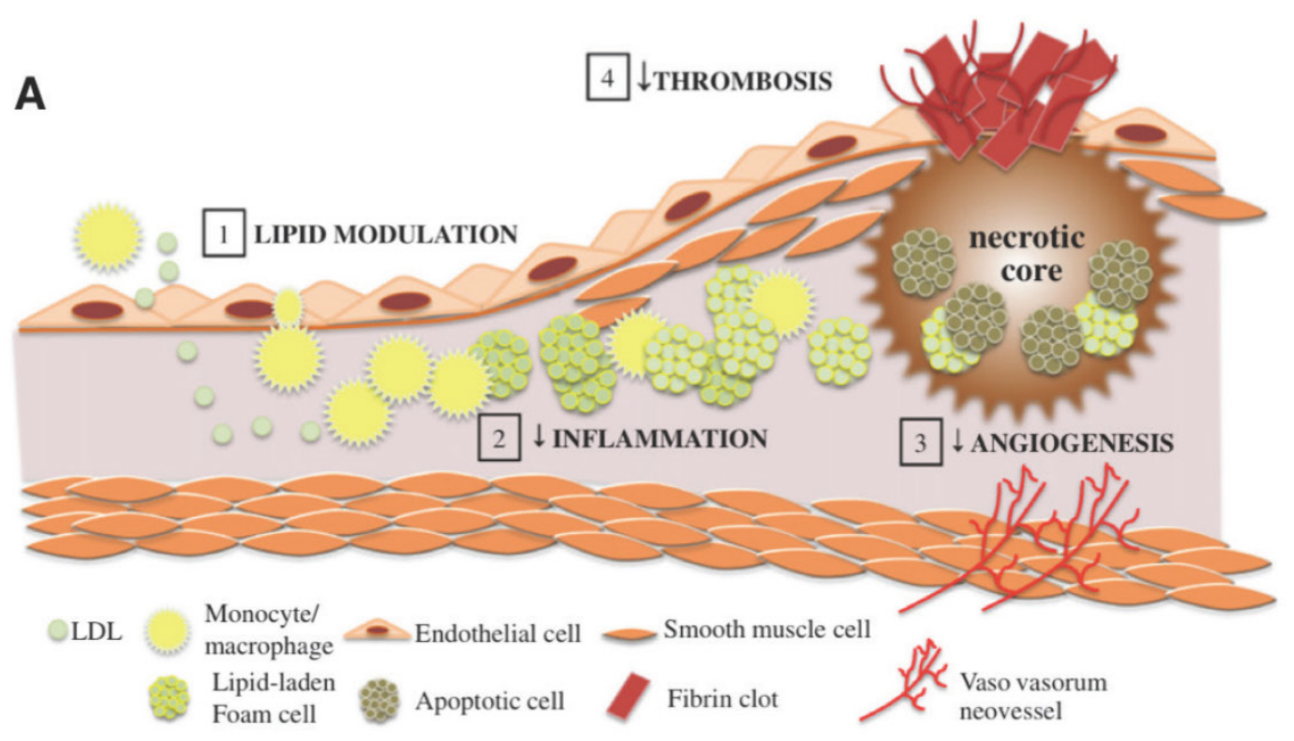

B
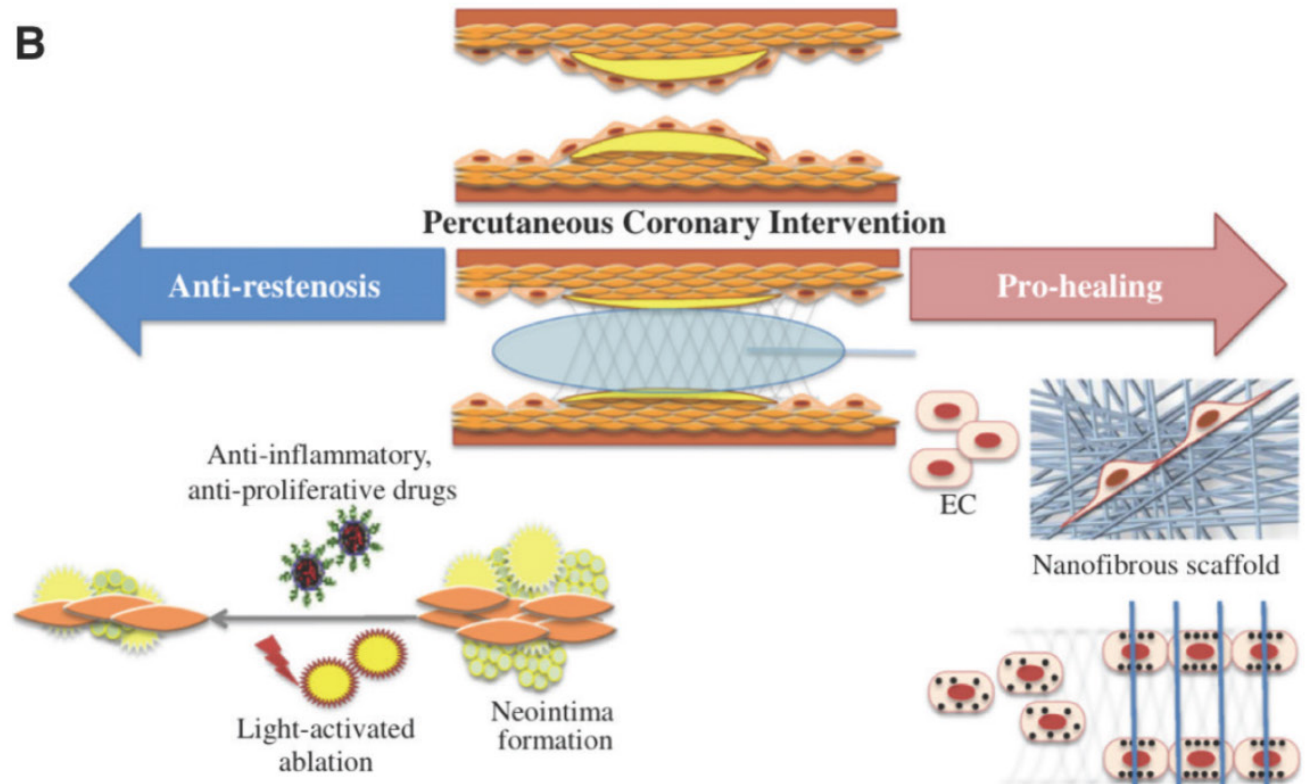

Nanofibrous scaffold

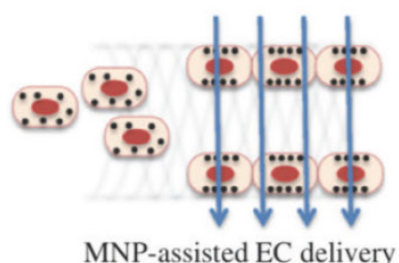

Figure I. (A) The progression of atherosclerosis and various therapeutic approaches. Such therapies involve lipid modulation of the blood, decreasing intra-plaque inflammation, thrombosis and angiogenesis. (B) Pro-healing and anti-restenosis approaches post PCI. Anti-inflammatory and anti-proliferative drug delivery as well as light-activated ablation, both of which use nanoparticles can be used to prevent restenosis. Nanofibrous scaffolds emulating extracellular matrix and magnetic nanoparticles delivering endothelial cells can be used to enhance stent strut endothelialization. Copyright @ $@ 2013$ Elsevier B.V. Reproduced with permission from [2]. 
Despite the initial success of BMS in PCI, early ultrasound studies indicated late restenosis in vessels with stents compared to those without[10]. In response to these concerns, research was propelled to limit such neoplastic effects with the delivery of antineoplastic drugs[6]. It was through this that the revolutionary drug-eluting stent (DES) was conceived[7]. The DES comprises of a metal scaffold surrounded by a degradable drug polymer coating and with its use, significant reductions in restenosis rates were seen[13-15]. The demand for DES increased dramatically and by 2004, $80 \%$ of all of all PCIs were employing this stent[16]. These included the sirolimus-eluting CYPHER ${ }^{\mathrm{TM}}$ stent (Cordis Corporation) and the paclitaxel-eluting TAXUSTM stent (Boston Scientific), which were both known to have dramatically low restenosis rates 6 months post-implantation[17, 18]. However, evidence began to mount against DES, with studies concluding late-stent thrombosis (ST) rates being higher than in BMS[19, 20]. ST has mortality rates of up $30 \%$ and is a potentially fatal complication [21].

Biodegradable stents (BDS) offer a promising alternative to conventional BMS and DES and it is perhaps interesting to note that the idea of semi-permanent absorbable stents were around long before the emergence of research on in-stent restenosis[22]. These stents provide drug release and vessel patency until it has healed and the stent then degrades into non-toxic compounds. The scaffolds are required to last from 6 to 12 months to allow the healing process to take place and thereafter the presence of the stent cannot provide any advantageous effects, hence the BDS is the most logical approach for the fourth stenting revolution[23-26]. The advantages of the BDS are manifold, with the most key being that it provides no triggers for ST, which is brought about by non-endothelialized stent struts and drug polymers remaining in vivo for long periods of time[27]. Other benefits of BDS may include the reduction in the amount of dual antiplatelet therapy (DAPT), facilitation of the return of vessel vasomotion, late luminal enlargement, late expansive remodelling and adaptive shear stress - all due to the lack of permanence of the stent[27]. Furthermore, the use of BDS allows future surgery or interventions to be performed in vessel areas which have had previous stenting, should this be warranted[27]. Lastly, the use of this stent will allow a level of psychological relief of concern to patients who dislike the idea of having a foreign material in their bodies for the rest of their lives[28].

Presently, BDS comes in either a metallic or polymeric form. There are many different types of polymer, each of which are made of different compo- sites, which give them varying degradation times. One of the most ubiquitous type of polymer is poly-L-lactic-acid (PLLA) polymer, which is found in many medical devices, including absorbable sutures, orthopaedic implants and soft-tissue implants [27, 29]. PLLA has also been studied as DES coating material and when combined with citric acid-cross-linked gelatin, the composite has demonstrated good anti-thrombogenic and drug elution properties (Figure 2)[29]. The use of the BDS however does not come without its concerns; namely that the polymers offer a reduced radial force when compared to stainless steel stents and have a decreased deformability/ ductility[27].

Biodegradable metal stents have also shown promise, most notably being the magnesium variety due to their fast degradation time of around 60-90 days[6]. This type of stent has been shown to have low thrombogenic action and the concentration of magnesium released is believed to be minute when compared to the magnesium concentration of plasma at $0.7-1.0 \mathrm{mmol} / \mathrm{L}[25,30]$. Moreover, magnesium is not detectable under magnetic resonance imaging (MRI) or computed tomography (CT), which has important implications as it means it does not cause the appearance of artefacts[6]. Nonetheless it is important to note that, as with the polymeric BDS, there are engineering hurdles in design and testing which much be overcome, such as reduced deformability or ductility[6].

There are currently numerous pre-clinical and clinical trials in place assessing BDS, and initial data has shown their use to be a definite feasible option[6]. It hoped that in the near-future, they will available for medical use and in doing so, may be an effective and superior alternative the current BMS and DES.

As for future stent designs, enhancements and improvements can be delivered by the use of nanoparticles (NPs) with specific interest in using a theranostic approach. Theranostics refers to using technology which has therapeutic and diagnostic potential, whereby it can not only advance knowledge of a current disease status, but also improve disease outcomes[31]. The essential benefit of theranostic nanomedicine lies in its ability to utilise patient-specific test outcomes to individualise therapies for better results, decreased cost and fewer side effects[31]. NPs have already shown great success in such areas, with particular mention to molecular imaging (especially MRI) and drug delivery[31]. We propose that the application of theranostic functionality in current stent designs can potentiate further improvements. Such advances in stents could include a higher therapeutic index and easy in vivo monitoring of in-stent drug delivery. Moreover, it could potentially provide not 
only a non-invasive alternative, but also ultrasensitive and precise diagnoses of in-stent stenosis and thrombosis due to enhanced visibility of disease biomarkers[31-35].

\section{Bioabsorbable Stents: Current Status}

Presently, there are over 14 different biodegradable stents (BDS) which are in preclinical and clinical testing worldwide[36]. Two of these stent types are used in clinical practice and have already attained their Conformité Européenne (CE) mark; the Absorb Bioresorbable Vascular Scaffold (BVS) (Abbott Vascular) for coronary artery disease and the Igaki-Tamai ${ }^{\circledR}$ stent (Kyoto Medical Planning Co., Ltd.) for peripheral vascular disease. Many stent struts are composed of polymers of lactic acid and specifically of poly-L-lactic acid (PLLA), with fewer numbers consisting of other types of polymers and metal alloys. Thus, the BDS can broadly be divided into polymer or metallic stents, which are discussed below.

\section{Dissolvable Metallic Stents}

The biodegradable or dissolvable metallic stents
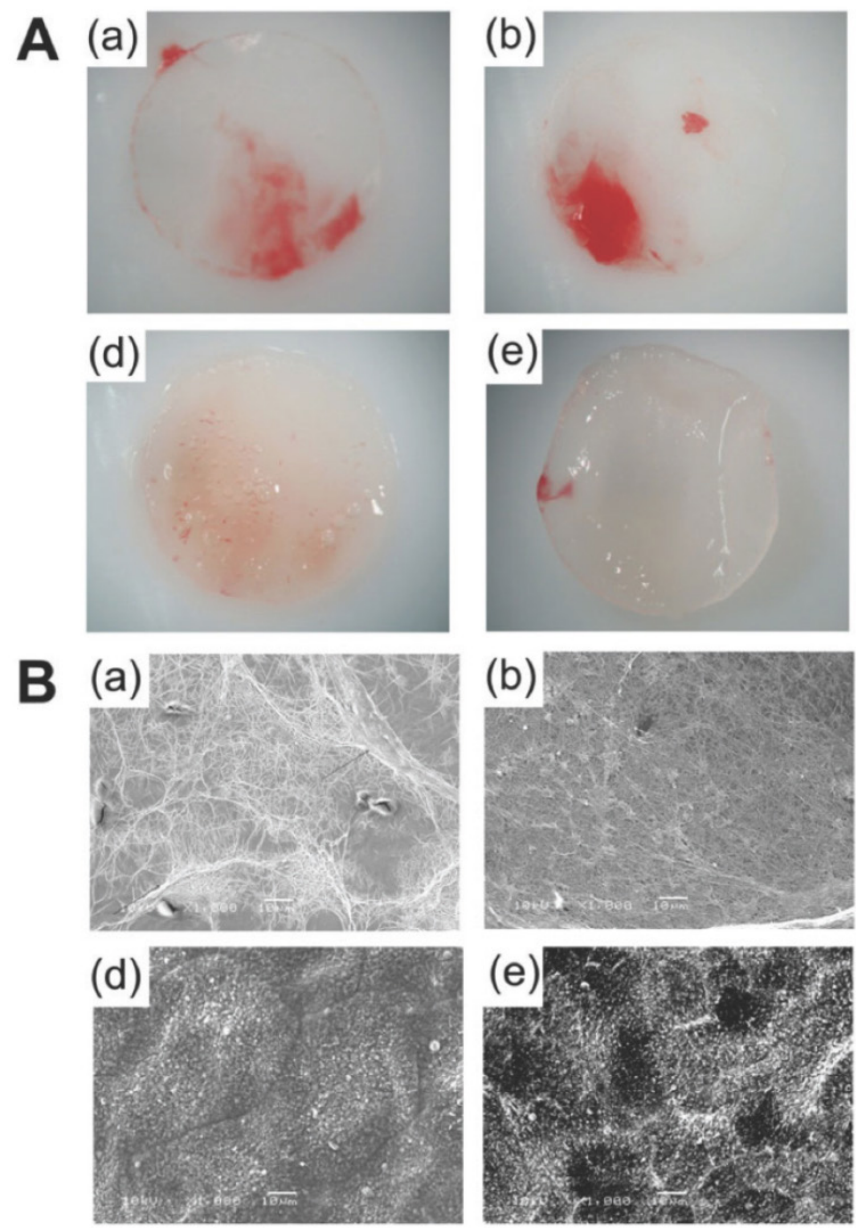

consist of either magnesium-based $(\mathrm{Mg})$ or iron-based (Fe) alloys[26, 37, 38]. The rationale behind using these particular metals lies in their relatively well understood toxicity and clearance profiles, which makes them logical candidates for metallic stent strut material. Their advantages and limitations are discussed in Table $1[26,39]$. These metals are alloyed with calcium $(\mathrm{Ca})$, zinc $(\mathrm{Zn})$ and manganese $(\mathrm{Mn})$ as they are well tolerated in the human body. The alloying of Fe with other metals is necessary to alter its ferromagnetism which can reduce MRI compatibility. As for magnesium, it is alloyed to decrease its degradation rate and increase its ductility and strength[40]. For instance, hot extruded $\mathrm{Mg}-\mathrm{Ca}$ alloy has an improved strength and ductility combination, with a tensile strength reaching $240 \mathrm{MPa}$ with $11 \%$ elongation[38]. Presently and to the best of the authors' knowledge, all but one Mg-based and Fe-based coronary BDS are still undergoing preclinical trials, with one Mg-based BDS (the DREAMS 1.0 scaffold) having already entered clinical trials[36, 38]. As for non-coronary applications, metallic BDS has previously been studied in the treatment of infrapopliteal artery lesions[41].
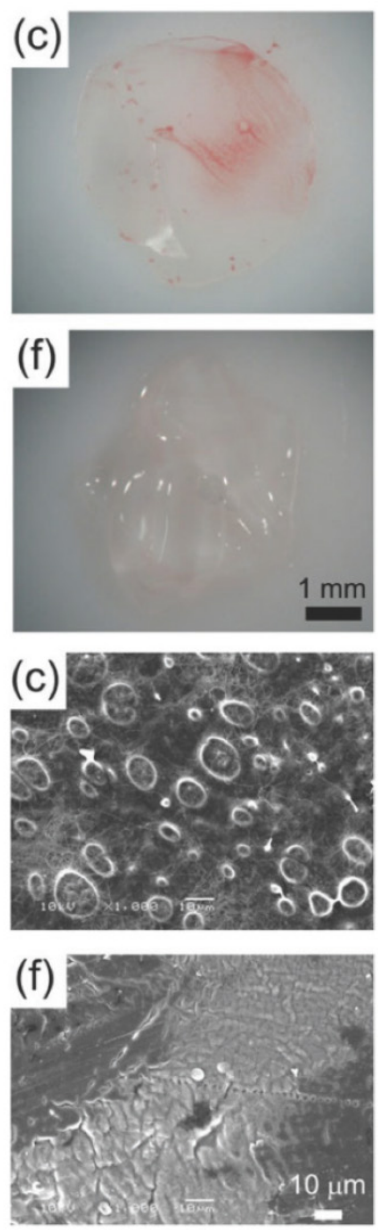

Figure 2. (A) PLLA and citric acid-crosslinked gelatin matrices demonstrated in pictures and (B) scanning electron microscope images. Such composites have been used as DES coating material which allows antithrombogenic and drug-eluting properties. The composite has varying ratios of PLLA to citric acid-crosslinked gelatin: 100/0 (a), 80/20 (b), 60/40 (c), 40/60 (d), 20/80 (e), 0/100 (f). Copyright () 2012 Wiley Periodicals, Inc. Reproduced with permission from [29]. 
As the only bioabsorbable metallic coronary stent in clinical trials as of yet, the drug-eluting bioabsorbable magnesium stent, DREAMS 1.0 (Biotronik SE \& Co. KG), has a degradation time of 9-12 months[42]. This Mg-based BDS is evaluated in the pioneering first-in-man BIOSOLVE-1 trial. In this prospective study, the DREAMS 1.0 scaffold was implanted in 46 patients treated for 47 single de novo coronary artery lesions and at 12 months, the MACE rate was found to be $7 \%$, with no cardiac deaths or scaffold thrombosis[42].

Table I. Advantages and limitations of dissolvable metallic stents (Fe and $\mathrm{Mg}$ alloys are mainly considered).

\begin{tabular}{ll}
\hline Advantage & Limitation \\
\hline $\begin{array}{l}\text { Relatively well known toxicity and } \\
\text { clearance profiles }\end{array}$ & $\begin{array}{l}\text { Lack of visibility on angi- } \\
\text { ography }\end{array}$ \\
$\begin{array}{l}\text { Fast degradation time of around } \\
\text { 60-90 days }\end{array}$ & Reduced deformability \\
Low thrombogenic action & Reduced ductility \\
\hline
\end{tabular}

\section{Biodegradable Polymeric Stents}

As well as biodegradable metallic stents, there are also biodegradable polymeric stents which employ a wide variety of polymers, such as those made from lactic acid, glycolic and caprolactone[22, 43-45]. However, by far the most used polymer for BDS is composed of poly-L-lactic acid (PLLA). PLLA is already found in many medical items, including dissolvable sutures and various implants, and itself has a degradation time of 12-18 months[27]. Another polymer used is the polymer-tyrosine derived polycarbonate, which is used in the ReZolve ${ }^{\circledR}$ stent (REVA Medical Inc.) and it primarily degrades into L-tyrosine[6]. Many biodegradable stents have a degradation time between 12 to 36 months and the two that are CE marked (first generation Igaki-Tamai stent and Absorb BVS 1.1) have a degradation period of 2-3 years[36, 46]. Importantly though, the first generation Igaki-Tamai stent is no longer used for human coronary implants since large guide catheters are needed for insertion and heated contrast agents are necessary for stent deployment, which could potentially cause damage to the vessel wall[28]. This stent is now under use peripherally, but preclinical trials are underway for a second generation Igaki-Tamai scaffold for coronary application which

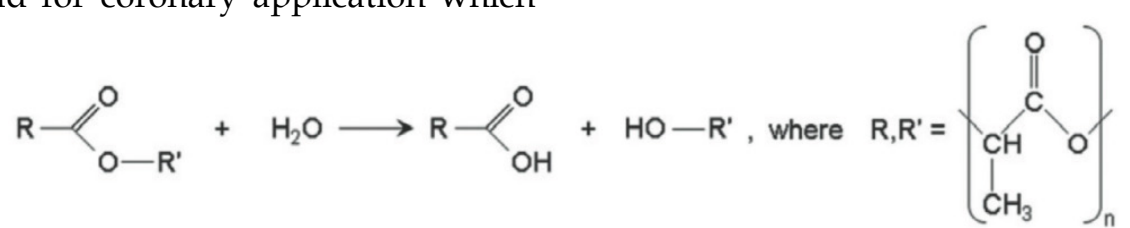

employs a smaller catheter for insertion[36]. Thus, presently the only CE marked coronary stent in ongoing clinical trials is the Absorb BVS.

\section{Absorb Bioresorbable Vascular Scaffold (BVS)}

The Absorb BVS is composed of a PLLA backbone and coated with poly-D,L-lactide (PDLLA) and $8.2 \mu \mathrm{g} / \mathrm{mm}$ of everolimus (an anti-proliferative drug) in a 1:1 ratio[27, 47]. The PDLLA allows release of everolimus in a controlled manner and by 30 days, $80 \%$ of the drug is eluted. Although the stent is radiolucent, two platinum radio-opaque markers in each end allow for clear identification on fluoroscopy and aids accurate post-dilatation and stent implantation[48]. Both polymers of the stent eventually degrade into lactic acid through metabolism in the Krebs cycle, a process which takes up to 2 years to complete[47].

\section{Hydrolysis of PLA}

Since the BVS employs the PLA family of polymers, it is necessary to understand how such polymers hydrolyse in vivo over time. The hydrolysis occurs through a nucleophilic substitution that is catalysed by either acids or bases, for example by water catalysis, which causes a chain scission reaction at an ester bond (Figure 3) [49].

Since the polymer contains one ester bond at each subunit, chain scission can happen anywhere along the chain. This hydrolysis of the polymer occurs via bulk degradation whereby breakdown occurs throughout the whole polymer as opposed to initial superficial degradation[50]. Under such circumstances, the rate of hydrolysis can be predicted using the Pitt et al third-order kinetics theory which states that the hydrolysis rate is dependent upon the concentration water, ester bonds and carboxylic acid end groups[51]. We are able to deduce the hydrolytic degradation rate from the slope of the line drawn by using the equation $[52,53]$ :

$$
\ln \left[\mathrm{M}_{\mathrm{n}}(\mathrm{t}) / \mathrm{M}_{\mathrm{n}}(0)\right]=-k t
$$

Where: $M_{n}(t)$ is the number-average molecular weight after degradation time ' $t$ ', $M_{n}(0)$ is the number-average molecular weight before degradation, and $k$ is the hydrolytic degradation constant.

Figure 3. Hydrolytic degradation of the PLA polymer family. Copyright @ 2013 Europa Digital \& Publishing. Reproduced with permission from [49]. 
The degradation of the PLLA scaffold can be categorised into 3 stages. Firstly, water diffuses into the scaffold and hydrolyses ester bonds resulting in a decreased molecular weight. Secondly, there is scission of amorphous chains linking crystalline areas whereby scaffold cracks may be observed. Lastly, polymer chains are able to diffuse out and be degraded by the body[49].

\section{Design Specifications of BVS}

As well as understanding polymer hydrolysis of BVS, various design specifications of BVS 1.0 and 1.1 can be appreciated. The first generation of the BVS (BVS 1.0) consists of repeated circumferential out-of-phase zig-zag loops joined together by thin bridges (Figure 4, A and C)[54]. The BVS 1.0 was assessed in the ABSORB Cohort A trial which included 30 patients. This trial revealed the device was safe and feasible for clinical use, with a 3 year MACE rate remaining at a low 3.4\%[55]. After the ABSORB Cohort A trial, various improvements followed such as an alteration in the processing resulting in a longer duration of radial support, a new in-phase zig-zag design which permitted uniform vessel support and allowed everolimus to be applied to the stent more consistently. Other enhancements included allowance for storage at room temperature, when before it was necessary for storage below $-20^{\circ} \mathrm{C}$ and the improvement of stent security to prevent dislodgement. These enhancements resulted in the newer, second generation BVS 1.1 (Figure 4 B, D and E) in which important design aspects are discussed below $[49,54]$.

\section{Phases of BVS}

Many design considerations of the BVS have been put in place to mimic the traditional metallic DES, such as those that allow achievement of high radial strength and flexibility[49]. These stent characteristics are desirable until the vessel has healed, after which the scaffold has no added benefit and can be a hindrance for vessel dilatation, for example when exercising[49]. The scaffold degradation in the BVS naturally warrants different design criteria to metallic stents and consequently it can be said that there are two distinct physiological responses in the two stent scenarios. This connection between BVS stent phases and physiological responses is depicted in Figure 5 . The stent phases can broadly be divided into 3 distinct sections: revascularisation, restoration and finally resorption.
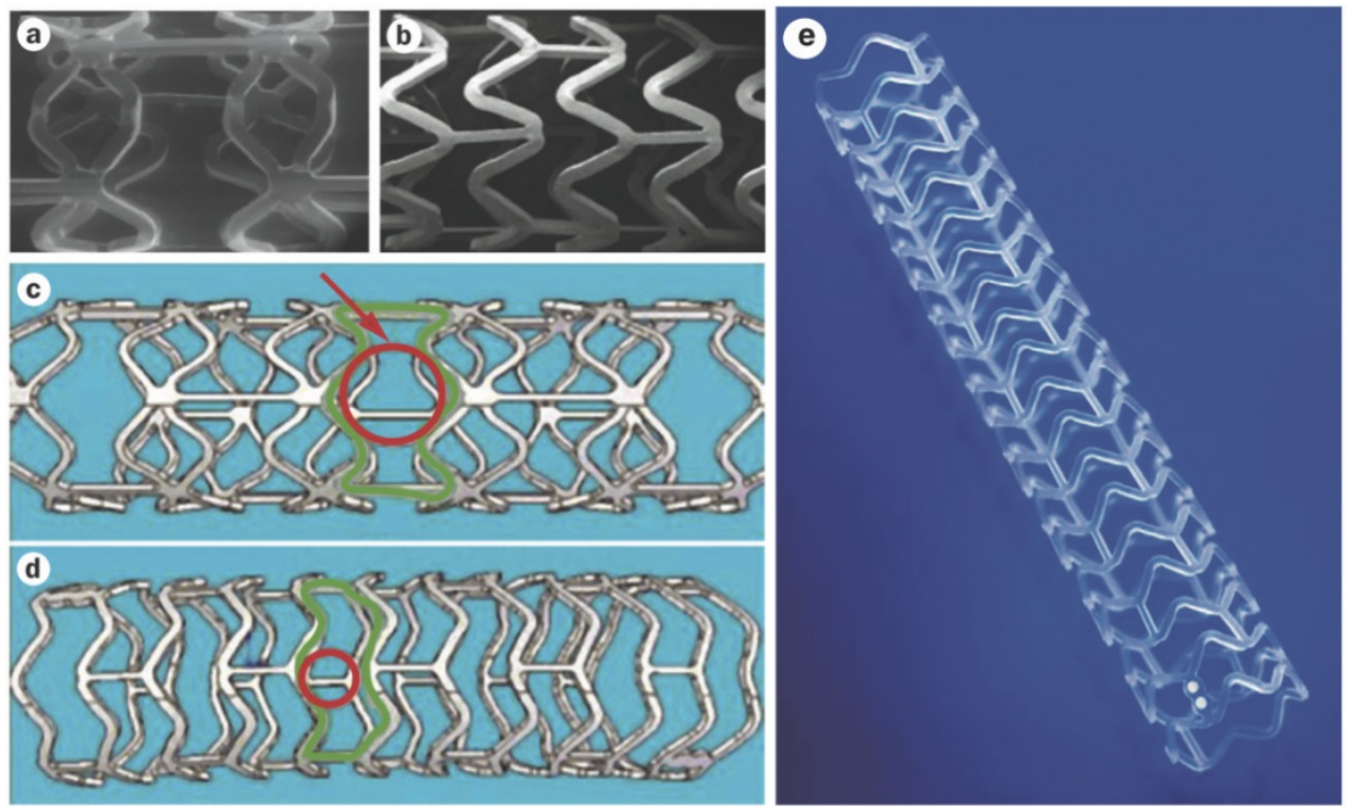

Figure 4. (A and C) BVS I.0, the first generation BVS with out-of-phase zig-zag loops and (B, D and E) BVS I.I, the second generation with in-phase zig-zag loops. (C) The red circular and green outlines demonstrate the unsupported cross sectional areas which are larger in BVS I.0 than in (D) BVS I.I. (E) Illustration the newer in-phase zig-zag loops which allow more uniform vessel support and increased consistency of drug application. Copyright $(2) 2013$ Nature Publishing Group, a division of Macmillan Publishers Limited. Copyright (C) 2013 Europa Digital \& Publishing. Reproduced with permission from [54] [49]. 


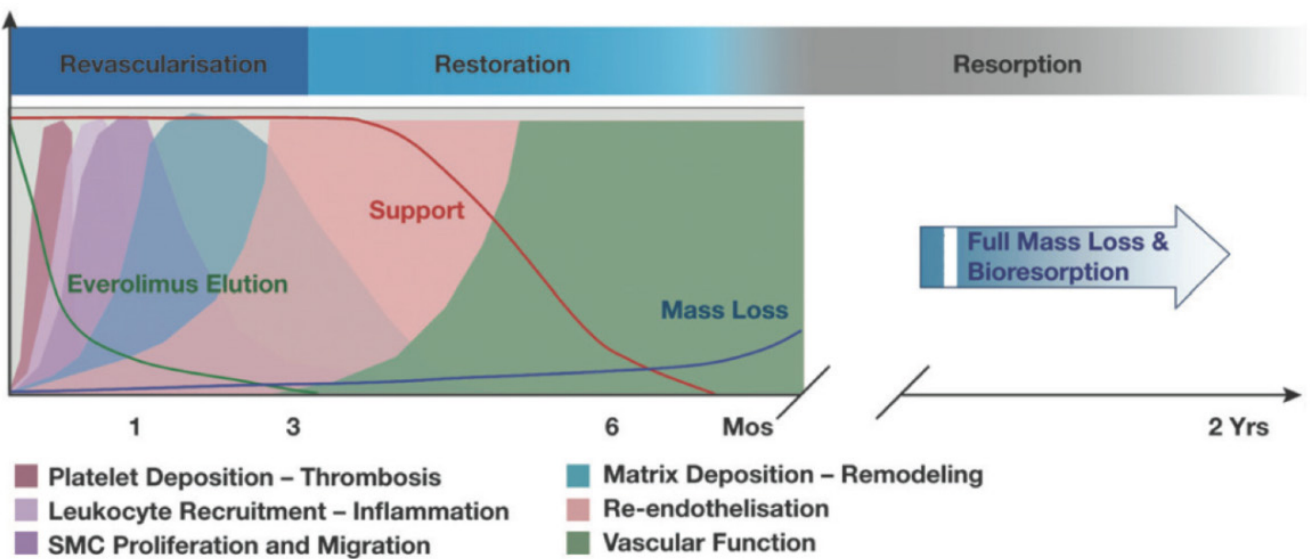

Figure 5. A graphical representation of the 3 BVS (I.I) stent phases. The phases are revascularisation, restoration and resorption which all coincide with various physiological responses. $80 \%$ of everolimus-elution (green curve) occurs within 28 days of implantation and luminal support (red curve) is provided for at least 3 months. Copyright (c) 2013 Europa Digital \& Publishing. Reproduced with permission from [49].

During the revascularisation phase, the BVS should emulate metallic stents as closely as possible in their: good deliverability to the target site, deployment of scaffold with minimum recoil, drug delivery at a controlled rate and high radial strength. Good deliverability of the stent to its necessary site is essential and scaffold flexibility is important for this to be achieved. Head to head tests of flexibility between the ABSORB Cohort B device (which is the BVS 1.1, a second generation BVS to BVS 1.0) and XIENCE V (a conventional DES, Abbott Vascular) have indicated that, in fact, the BVS has greater flexibility at a statistically significant level (Figure 6)[49]. It is important to note that catheters during testing were kept the same, so catheter flexibility had no bearing on the result. As for radial strength, the BVS 1.1 used in the ABSORB Cohort $B$ trial is similar to that of XIENCE V and other metallic DES which demonstrates the device has the appropriate radial strength parameters, as shown in Figure 7[49]. The second phase of the BVS, otherwise known as the restoration phase marks the transition from an actively supporting stent to a more passive scaffold whereby vasomotion of the vessel is restored. The final resorption stage starts when PLA is degraded into lactic acid and is released into the surrounding region, such as tissue and blood.

\section{Clinical Trials of BVS}

The abundance of clinical trials dedicated to the BVS attest to its promise as being the first bioabsorbable polymeric stent to be approved by the United States Food and Drug Administration (FDA). Table 2 summarises the trials of BVS. These clinical trials can broadly be categorised into comparative stent studies, whether between the two BVS generations or between BVS and other stents[56-62] or BVS assessment studies[47, 63-69].

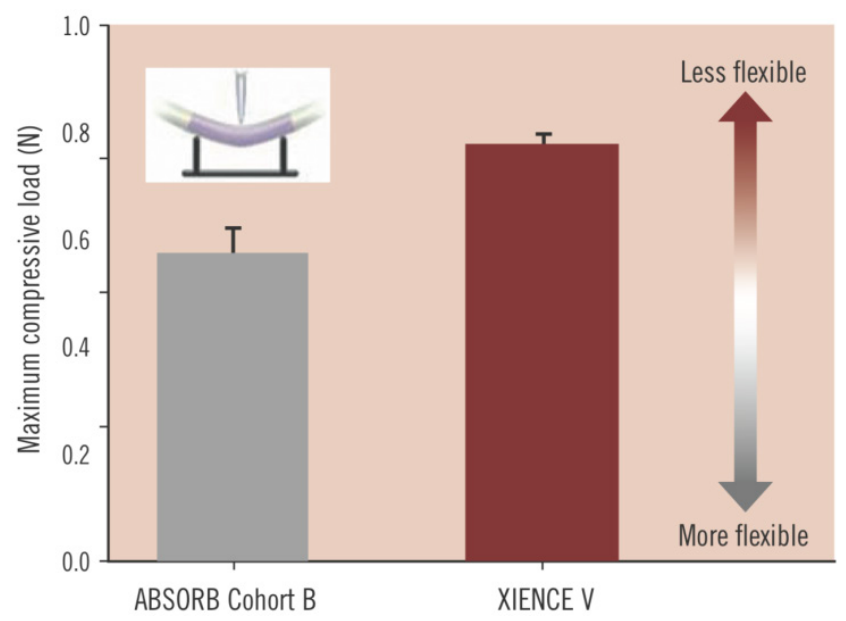

Figure 6. The maximum compressive load needed to bend the ABSORB Cohort B device (BVS I.I) and XIENCE V (a metallic DES), which is an indication of flexibility. The BVS I.I has greater flexibility at a statistically significant level, where $p=0.004$. Copyright $(2013$ Europa Digital \& Publishing. Reproduced with permission from [49].

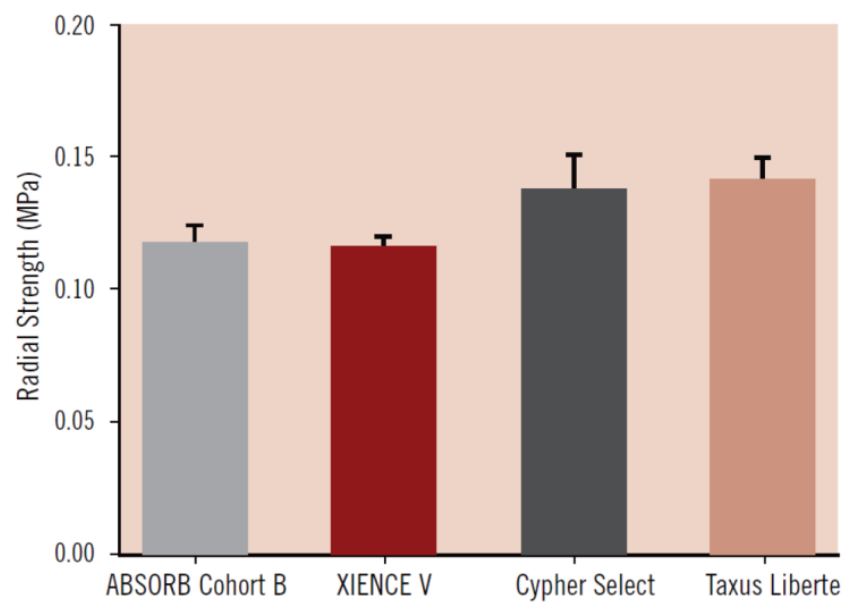

Figure 7. Acute radial strength of the ABSORB Cohort B device (BVS I.I) compared to metallic DES such as XIENCE V, Cypher Select and Taxus Liberte. Data obtained using MSI RX550 radial expansion force gauge. Copyright () 2013 Europa Digital \& Publishing. Reproduced with permission from [49]. 
Table 2. A summary of Bioresorbable Vascular Scaffold (BVS) Stent clinical trials.

\begin{tabular}{|c|c|c|c|c|c|c|}
\hline Author & Date & Trial name & $\begin{array}{l}\text { Number of pa- } \\
\text { tients }\end{array}$ & Aim & Clinical endpoints & Ref \\
\hline $\begin{array}{l}\text { Tanimoto } \\
\text { et al }\end{array}$ & 2007 & $\begin{array}{l}\text { ABSORB } \\
\text { SPIRIT FIRST } \\
\text { and II trials }\end{array}$ & $\begin{array}{l}54 \\
\text { (total of analyzed } \\
\text { patients from all } \\
\text { trials) }\end{array}$ & $\begin{array}{l}\text { To assess and compare } \\
\text { acute stent recoil in vivo of } \\
\text { BVS with cobalt chromium } \\
\text { EES. }\end{array}$ & $\begin{array}{l}\text { BVS stent recoil is slightly larger, but comparable } \\
\text { to that of cobalt chromium EES suggesting good } \\
\text { radial strength similar to it. }\end{array}$ & [62] \\
\hline
\end{tabular}

$\begin{array}{lll}\begin{array}{ll}\text { Ormiston } \\ \text { et al }\end{array} & 2008 \text { ABSORB cohort } 30 \\ & \text { A trial }\end{array}$

Surreys et 2009 ABSORB

al

30

\begin{tabular}{|c|c|c|}
\hline \multirow{2}{*}{$\begin{array}{l}\text { Gomez-Lar } \\
\text { a et al }\end{array}$} & 2010 & $\begin{array}{l}\text { SPIRIT FIRST } \\
\text { and II trials }\end{array}$ \\
\hline & & $\begin{array}{l}\text { ABSORB cohort } \\
\text { B trial }\end{array}$ \\
\hline $\begin{array}{l}\text { Okamura } \\
\text { et al }\end{array}$ & 2010 & $\begin{array}{l}\text { ABSORB trials } \\
\text { (cohort } \mathrm{A} \text { and } \mathrm{B})\end{array}$ \\
\hline
\end{tabular}

Brugaletta 2011 ABSORB trials 60 et al (cohort A and B)

$\begin{array}{lll}\begin{array}{l}\text { Gomez-Lar } 2011 \\ \text { a et al }\end{array} & \text { RESOLUTE trial } & \begin{array}{l}44 \\ \text { (total }\end{array} \\ & \begin{array}{l}\text { ABSORB cohort } \\ \text { B trial }\end{array} & \begin{array}{l}\text { pati } \\ \text { trials) }\end{array} \\ & \begin{array}{ll}\text { Gomez-Lar } 2011 \\ \text { a et al }\end{array} & \begin{array}{l}\text { ABSORB trials } \\ \text { (cohort A and B) }\end{array}\end{array}$

191

(total of analyzed patients from all

trials)

8

60

\section{4}

(total of analyzed

patients from both trials)

24

a et al

(cohort $\mathrm{A}$ and $\mathrm{B}$ )

Onuma et 2011 ABSORB trial 147 (total of anaal (cohort A and B) lyzed patients SPIRIT FIRST from all trials) and II trials

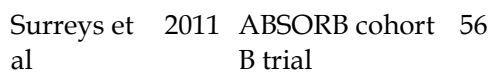

To assess the feasibility At 6 month follow up the neointimal area was and safety of the BVS 1.0. minimal and low stent area obstruction was observed.

At 1 year post implantation, the rate of MACE was $3.3 \%$ and there were no stent thromboses.

This study concludes that the BVS is feasible, with minimal neointimal hyperplasia and low stent area obstruction.

To assess the safety of BVS Luminal area enlargement was found using OCT using clinical outcomes and intravascular ultrasound between 6 months and various imaging tech- and 2 years, which was due to a decrease in plaque niques.

size.

At 2 year follow up the BVS was safe with no cardiac deaths or stent thromboses recorded, and only one myocardial infarction (non-Q wave). This study concludes that at 2 years the BVS was bioasorbed, there was a restoration in vasomotion, restenosis was prevented and is clinically safe.

To assess the differences in BVS produces a less marked change in vessel vessel curvature and an- geometry, with regards to vessel angulation and gulation following implantation of either MPS curvature, compared to MPS, suggesting that is it more conformable.

everolimus DES Xience V or BVS 1.1

To compare strut distribu- BVS 1.1 has a different longitudinal strut distribu- [60] tion in vivo of BVS 1.0 and tion to BVS 1.0, which indicates that the new stent BVS 1.1. as a reduced maximum circular unsupported cross sectional area (MCUSA).

This study concludes that this may reduce recoil.

To compare the polymeric A less reduced DC and NC was observed in cohort [56] struts of the first genera- B (Revision 1.1) at 6-month follow up using tion (Revision 1.0) BVS to IVUS-VH compared to cohort A (Revision 1.0). the second generation This study suggests and concludes that the second (Revision 1.1) BVS. generation BVS is more durable mechanically.

To assess the vessel neoin- BVS showed a similar neointimal response in timal response following terms of amount and distribution to Xience $\mathrm{V}$ at 1

implantation of MPS year follow up using OCT.

everolimus DES Xience $\mathrm{V}$ or BVS 1.1.

To assess the difference in Neointimal thickness, neointimal area, luminal neointimal response, bio- losses, absolute and relative shrinkages were resorption process and late higher in BVS 1.0 than BVS 1.1 at 6 month follow shrinkage between BVS 1.0 up.

and BVS 1.1 and using This study concludes that BVS 1.1 has less late OCT.

shrinkage and less neointimal growth when compared to BVS 1.0 at 6 months, indicating a difference in stent degradation.

To assess and compare the The absolute acute recoil is higher in BVS 1.1 acute recoil in vivo of BVS compared to Xience V and similar to BVS 1.0, but 1.0 and BVS 1.1 with these differences are not statistically significant. Xience V. This study suggests that appropriate vessel sizing, pretreatment of stenotic lesions and post-treatment dilatation may lead to recoil reduction.

To demonstrate that the Scaffold area stayed unchanged on IVUS and early scaffold area shrink- OCT. Radiofrequency backscattering and echoage in BVS 1.1 is sustained genicity of the stent struts decreased. Despite the and not delayed by a few scaffold area reduction, pharmacological vasomo- 


\begin{tabular}{|c|c|c|c|c|c|c|}
\hline $\begin{array}{l}\text { Brugaletta } \\
\text { et al }\end{array}$ & 2012 & $\begin{array}{l}\text { ABSORB cohort } \\
\text { B trial }\end{array}$ & 58 & $\begin{array}{l}\text { months. } \\
\text { To assess the circumferen- } \\
\text { tial healing process of } \\
\text { ABSORB BVS (Revision } \\
\text { 1.1) at } 6 \text { months and } 12 \\
\text { months. }\end{array}$ & $\begin{array}{l}\text { tion was restored. } \\
\text { No difference found between } 6 \text { months and } 12 \\
\text { months in relation to the neointima area and neo- } \\
\text { intima mean thickness using OCT, however } \\
\text { symmetry of the neointima thickness was higher } \\
\text { at } 12 \text { months. } \\
\text { This study suggests and concludes that it is possi- } \\
\text { ble to accurately quantify the circumferential } \\
\text { healing process of scaffolds and the formation of a } \\
\text { thick neointima layer can be used as a 'cap' to seal } \\
\text { a thin cap atheroma. }\end{array}$ & [63] \\
\hline Dudek et al & 2012 & $\begin{array}{l}\text { ABSORB cohort } \\
\text { A trial }\end{array}$ & $\begin{array}{l}29 \text { at } 6 \text { months } \\
27 \text { at } 4 \text { years }\end{array}$ & $\begin{array}{l}\text { To assess the } 4 \text { year clinical } \\
\text { outcomes following } \\
\text { ABSORB BVS implanta- } \\
\text { tion. }\end{array}$ & $\begin{array}{l}\text { ID-MACE remained at a low } 3.4 \% \text { without any } \\
\text { scaffold thrombosis at } 4 \text { year follow up to BVS } \\
\text { implantation. }\end{array}$ & [65] \\
\hline Sarno et al & 2012 & ABSORB & 30 & $\begin{array}{l}\text { To assess the } \\
\text { vaso-reactivity of the ves- } \\
\text { sel and echogenicity of the } \\
\text { stent at } 2 \text { years following } \\
\text { BVS } 1.0 \text { implantation. }\end{array}$ & $\begin{array}{l}\text { During the bioabsorption of BVS there is also } \\
\text { re-establishment of both endothelial and } \\
\text { non-endothelial dependent vasomotion at } 2 \text { year } \\
\text { follow up, along with lumen area enlargement. }\end{array}$ & [68] \\
\hline Diletti et al & 2013 & $\begin{array}{l}\text { ABSORB cohort } \\
\text { B trial }\end{array}$ & 101 & $\begin{array}{l}\text { To assess the impact of } \\
\text { vessel size in long term } \\
\text { clinical, angiographic and } \\
\text { IVUS outcomes after } \\
\text { ABSORB BVS implanta- } \\
\text { tion. }\end{array}$ & $\begin{array}{l}\text { Similar clinical, angiographic and IVUS outcomes } \\
\text { seen in small }(<2.5 \mathrm{~mm}) \text { and large }(>2.5 \mathrm{~mm}) \text { ves- } \\
\text { sels, however positive vessel remodelling and } \\
\text { significant late lumen enlargement seen in smaller } \\
\text { vessels. }\end{array}$ & {$[64]$} \\
\hline \multirow[t]{2}{*}{$\begin{array}{l}\text { Mu- } \\
\text { ramatsu et } \\
\text { al }\end{array}$} & 2013 & $\begin{array}{l}\text { ABSROB-EXTE } \\
\text { ND single arm } \\
\text { trial }\end{array}$ & $\begin{array}{l}672 \\
\text { (total of analyzed } \\
\text { patients from all } \\
\text { trials) }\end{array}$ & $\begin{array}{l}\text { To assess the incidence of } \\
\text { SBO following BVS im- } \\
\text { plantation }\end{array}$ & $\begin{array}{l}\text { BVS had a } 6 \% \text { incidence of SBO in } 435 \text { patients. } \\
\text { BVS is related to higher incidence of side branch } \\
\text { occlusion compared to EES Xience V. }\end{array}$ & [66] \\
\hline & & $\begin{array}{l}\text { SPIRIT FIRST } \\
\text { and II trials }\end{array}$ & & & & \\
\hline
\end{tabular}

\section{Design Considerations of Advanced Na- noparticles for Theranostics}

Theranostics refers to the emerging field of medical technology which provides the dual functionality of therapy and diagnostics on a single platform. The advantages of nanoparticles offering theranostics are multi-faceted (Figure 8) and may greatly improve stents of the future[70]. The scale of such therapeutic particles (such as those conjugated with drugs or genes) allow for longer circulation, delivery to specific sites, and improved ease of tracking delivery in vivo by embedding imaging trackers[71, 72]. Moreover, these solutions not only offer a controlled rate of therapy release but also protection of the implanted therapy itself from pre-mature degradation[71]. Likewise studies have shown an increase in drug therapeutic index when delivered using nanocarriers[35].

The use of theranostics nanoparticles (NPs) in the targeting and imaging of cancer cells have widely been studied, including malignancies of the lung, pancreas, breast, ovaries as well as many others[73-75]. There has been particular interest in the last 20 years of nanoparticle delivery to tumour sites through manipulation of their vascular hyperpermeability and abnormal lymphatic drainage[76-80], to which numerous nanocarriers are utilised currently, such as those of Abraxane ${ }^{\circledR}$ (Celgene Corporation) and Doxil® (Janssen Products, LP) [81-84].

There are many classes of theranostic NPs, with varying sizes and compositions (Figure 9)[85]. Such devices may be of immense value in stent systems since they may provide improved therapeutic pathways in the treatment of in-stent thrombosis and restenosis in comparison to current techniques as well as offer novel post-stent implantation imaging and diagnostic methods all integrated into a single theranostic stent platform. Furthermore, the stent can be considered as an implant, which therefore localizes the drug delivery (as opposed to systemic drug delivery), keeping potential toxicity to a minimum.

\section{Localized Drug Delivery}

Various DES using NPs for drug release have been studied in animal models in order to reduce late stent thrombosis and restenosis and such preclinical trials have demonstrated marked success and illustrate the potential role for NPs in localizing drug delivery in stents. For example, in vivo delivery of imatinib (an inhibitor of platelet-derived growth factor receptor through inhibition of receptor tyrosine kinase) by bioabsorbable polymeric NPs has shown a $50 \%$ reduction in in-stent restenosis when compared 
to BMS and fluorescein isothiocyanate (a fluorescent marker) eluting stents[86]. Likewise significant suppression in restenosis has been achieved in NP elution of both gene and drug (VEGF gene and paclitaxel) after 1 month, in comparison to the TAXUS paclitaxel-eluting stent[87]. Although gene or drug NP-eluting stents currently remain experimental and are not yet FDA approved[21], they offer a promising alternative to conventional drug delivery stent systems.

Since the BDS aims to circumvent late in-stent restenosis and thrombosis by eventual degradation of the polymer (or metal) which is proposed to be the initial trigger, it is possible that NP drug or gene elution could further effectively suppress such physiological responses. Such NPs, like liposomes, dendrimers or other forms, with drug or gene cargo may be designed for attachment to cell specific ligands like those on platelets or local smooth muscle cells for targeted delivery. Moreover, controlled delivery may be achieved through nanoparticle responsiveness to local cues, in order to maximise delivery at the target site and minimize systemic adverse effects.

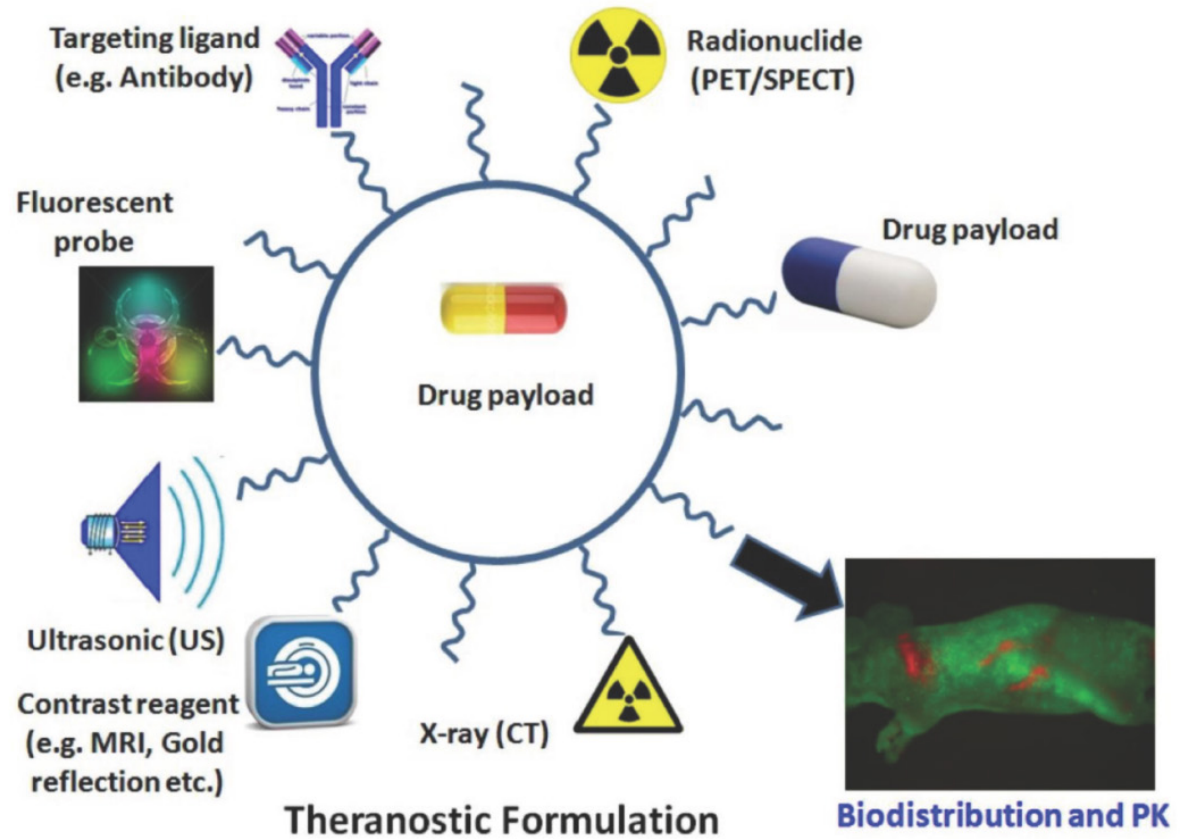

Figure 8. Depiction of a theranostic nanoparticle. Such multi-functionalized nanoparticles may be used for carrying a drug payload, molecular imaging, drug delivery, visualisation using fluorescence probes, X-ray imaging, contrast reagents, ultrasonic assistance and specific targeting of ligands. Copyright @ 20 I 3 Ivyspring International Publisher. Reproduced with permission from [70].
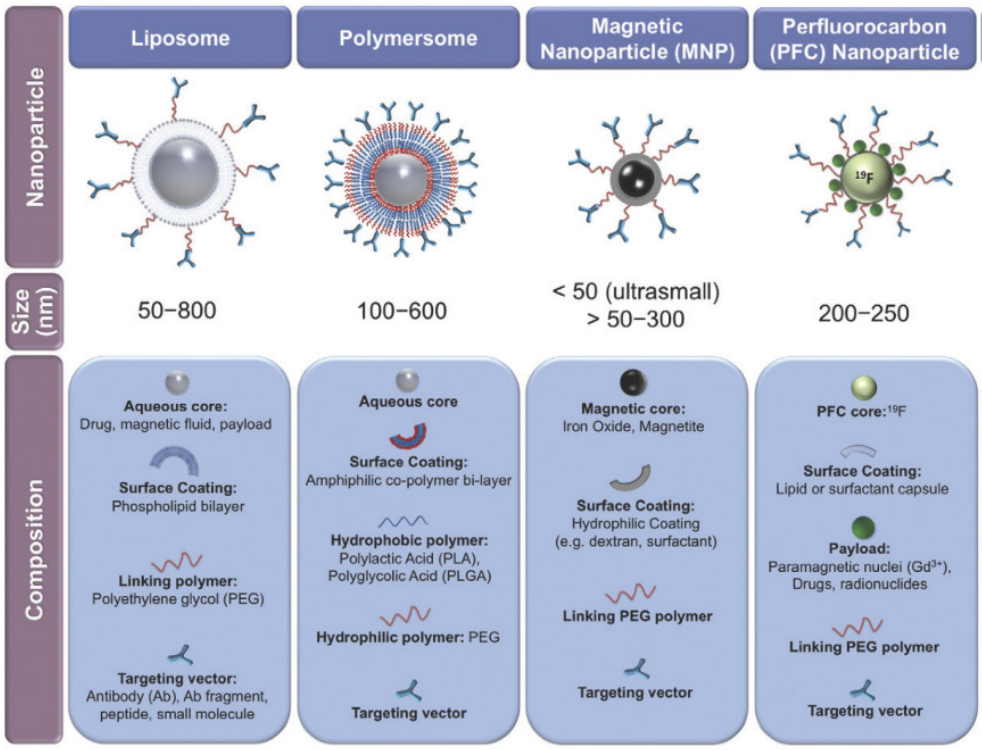

Dendrimer
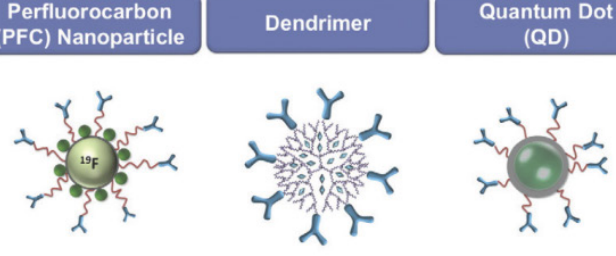

$100-600$
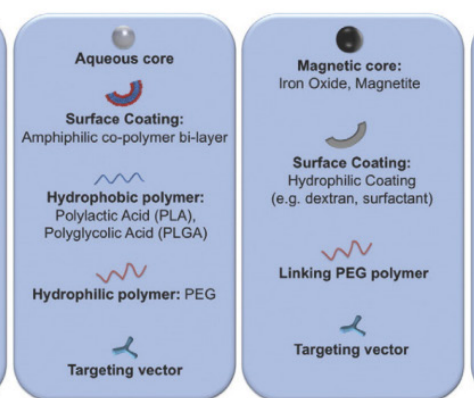

200-250

2-10
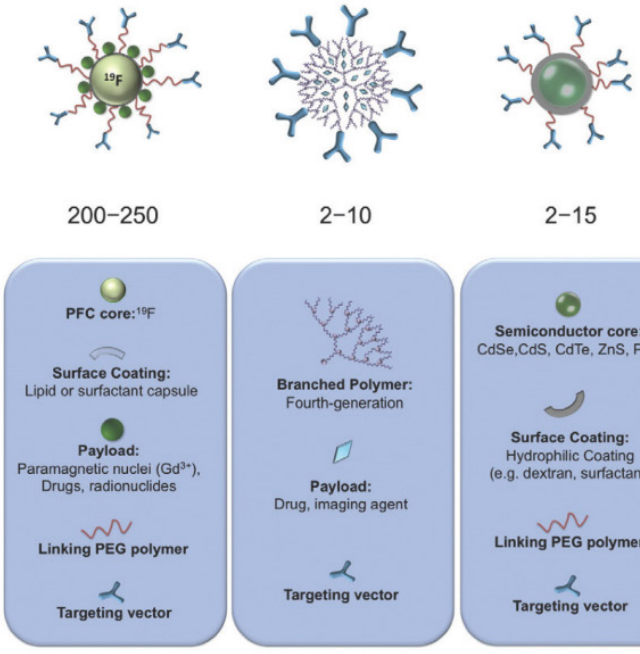

2-15 Figure 9. Classes
permission from [85]. 
There is an abundant array of NPs used in the treatment of vascular diseases, including vascular stenosis, MI and ischaemia of the lower limbs. The range of NPs used for these purposes can broadly be divided into various categories (Table 3) such as metallic NPs (such as iron NPs coated with gelatine [88]), carbon NPs (such as carbon-carbon NPs loaded with paclitaxel [89]) and polymeric NPs. Polymeric NPs include core shell NPs [90] (which are essentially polymeric micelles), poly(D,L-lactide) NPs [91] and also poly(lactic-co-glycolic) acid (PLGA) NPs encapsulating the VEGF gene [92] or pitavastatin [93]. Other polymeric NPs include poly(ethylene oxide)-modified poly(epsilon caprolactone) NP, otherwise known as PEO-PCL NPs, which have demonstrated to significantly increase anti-proliferative mechanisms of human aortic smooth muscle cells (Figure 10) [94]. Other NPs also exist in the form of liposomes combined with viral vectors [95, 96], liposomes delivering bisphosphonates (Figure 11) [97, 98] and lastly lipoplexes (cationic lipid and nucleic acid complexes) delivering the VEGF gene [99].

Many of these NPs have been used to treat vascular stenosis in experimental studies by delivery of anti-proliferative agents. For example, delivery of tyrphostins, a selective inhibitor of platelet-derived growth factor-receptor tyrosine kinase attenuates smooth muscle cell growth in vivo in swine and ex vivo in human arterial tissue and in a decreased in-stent

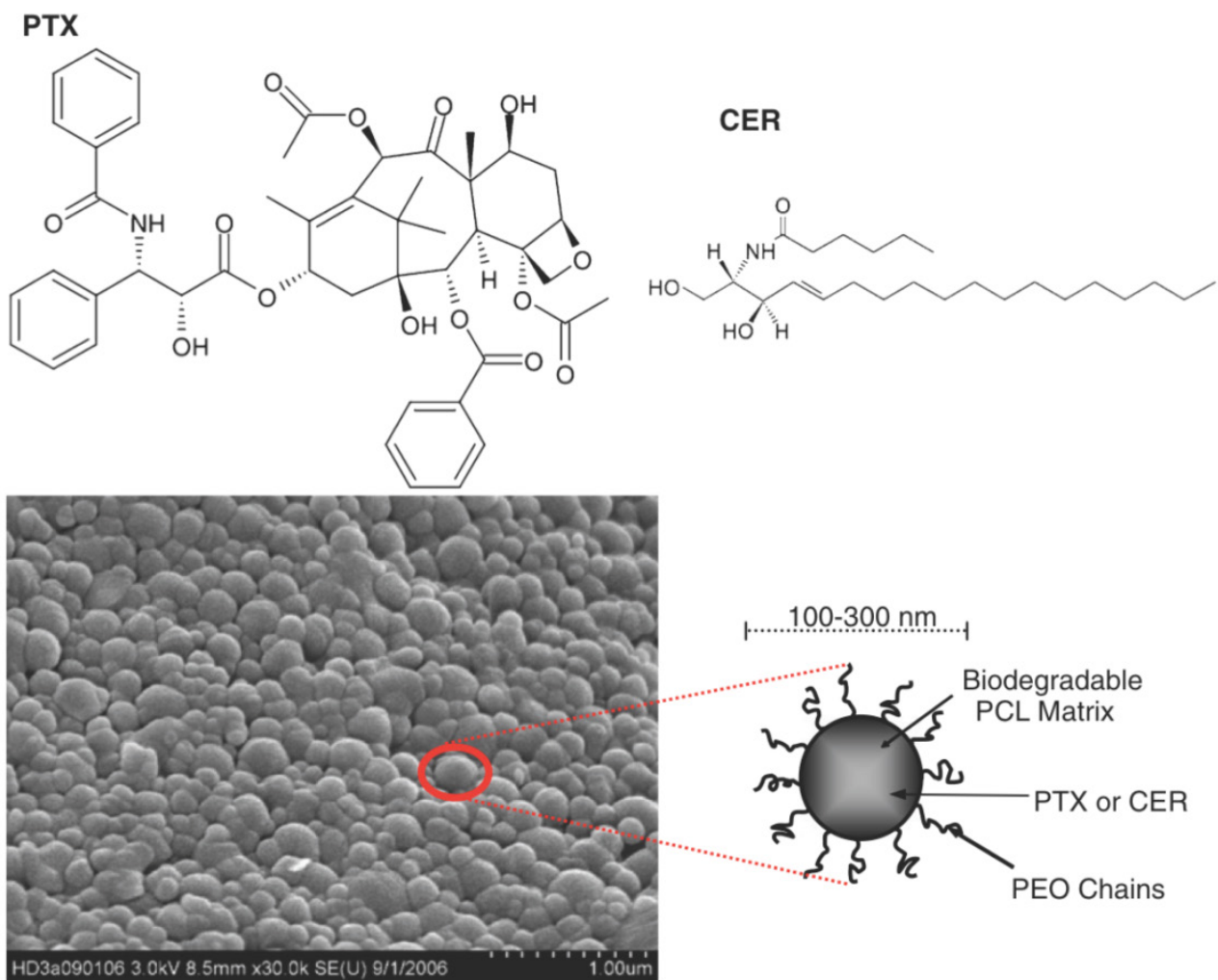

Figure 10. Paclitaxel (PTX) and Ceramide (CER) chemical structures and a scanning electron micrograph of poly(ethylene oxide)-modified poly(epsilon caprolactone) NP (PEO-PCL NP). Copyright @ 2008 Springer Science+Business Media, LLC. Reproduced with permission from [94]. 


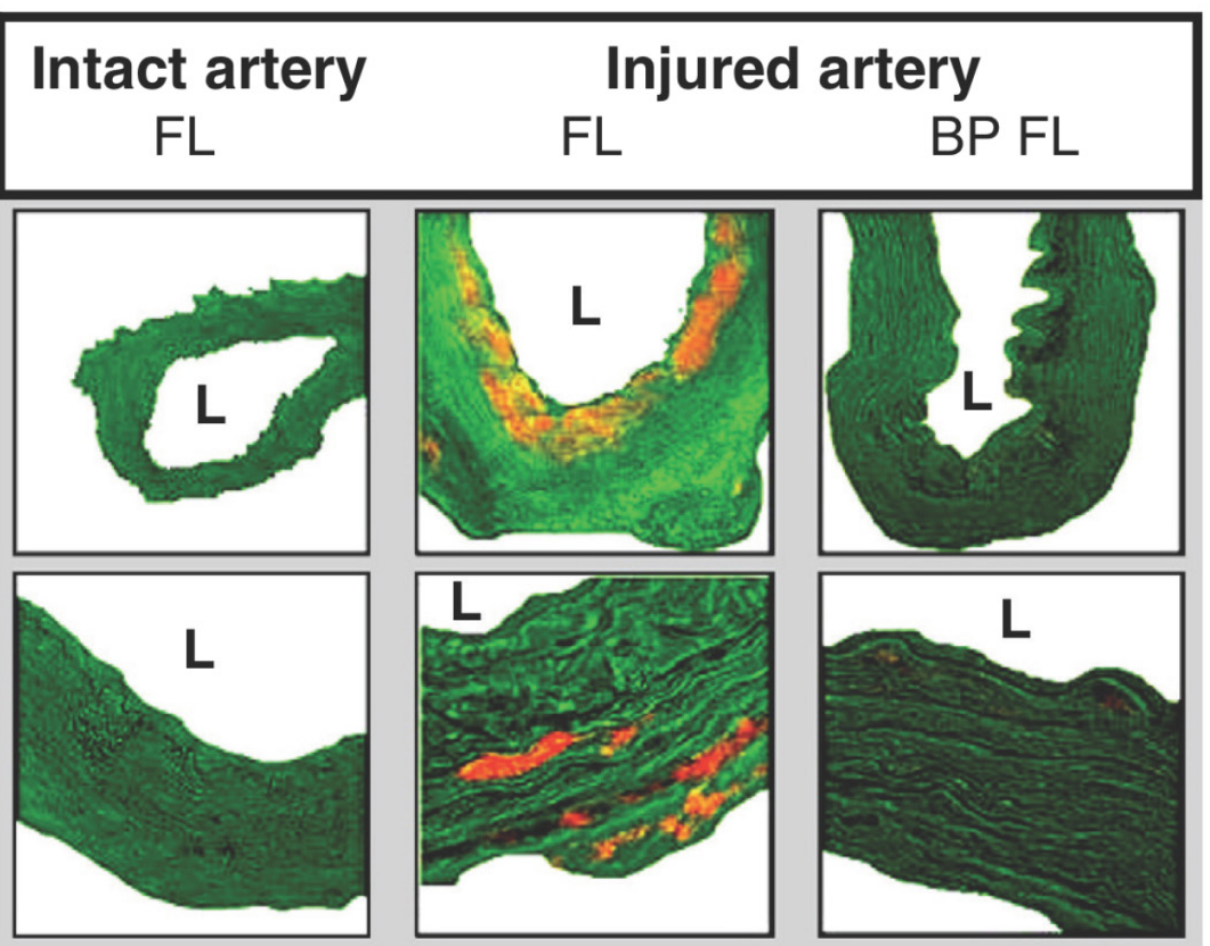

Figure II. Microscopy images demonstrating fluorescent liposomal uptake (orange) into vessel walls 24 hours after balloon injury. Lower row is of higher magnification. Liposomes are taken up following injury and with treatment of liposomal bisphosphonates, the vessel wall size is substantially reduced. $L=$ lumen. $F L=$ fluorescent liposomes. BP FL = bisphosphonate fluorescent liposomes. Copyright () 2013 Elsevier B.V. Reproduced with permission from [97, 98].

\section{Molecular Imaging Platform}

Molecular imaging may be defined as the use of molecular probes or contrast agents for the purposes of visualisation of in vivo tissues or pathways[101]. Current molecular imaging modalities include MRI, CT, single photon emission computed tomography (SPECT) and positron emission tomography (PET) and US, with the data of many techniques used concomitantly in what is referred to as multimodal imaging. For example, PET has been used in conjunction with MR and CT to combine the increased sensitivity and specificity of PET with the enhanced anatomical imaging of MR and CT [102]. Such techniques have allowed the imaging of various inflammatory markers using numerous tracers such as ${ }^{18} \mathrm{~F}-\mathrm{FDG}$ (2-deoxy-2-18 F-fluoro-D-glucose) Figure 12 [102]. There has been a recent surge in interest on the use of NPs as effective contrast agents, with studies demonstrating that they are able to current enhance imaging modalities by allowing for real-time assessment of drug location and release[103], improving sensitivity by increasing the contrast-to-noise ratio of surrounding tissues[33, 104], and they also have a high contrast agent payload[105].

Presently, optical coherence tomography (OCT) is increasingly favoured in coronary artery visualization due to its high resolution capabilities and allowance for imaging of various structures such as stent strut malappositions, post-stent restenoses, assessment of stent endothelialization, atherosclerotic plaque and thrombus formation[106]. However, OCT inherently remains an invasive procedure, with the insertion of an intravascular catheter. Furthermore, whilst OCT may be FDA-approved, there are a lack of large-scale studies demonstrating an association between OCT collected data and clinical outcomes[106, 107]. Thus, the use of nanoparticles in molecular imaging offers a possible non-invasive alternative to OCT as well as enhancement of current molecular imaging techniques.

Molecular imaging of cardiovascular diseases utilises NPs in one of 2 ways. This can be either through the use of NP contrast agent or the incorporation of contrast agents into various NPs such as liposomes and lipoproteins. Many NP devices have been used in the imaging of CVD and MI, as Table 4 and Figure 13 demonstrate [34]. There have been numerous iron oxide NPs created, such as superparamagnetic iron oxides [108, 109], oxazine fluorophore coated tat-cross-linked iron oxides [110, 111] (iron oxide NPs cross linked with trans-activator of transcription protein of HIV, all to which oxazine fluorophores are conjugated) and monocrystalline iron oxides [112, 113]. Animal studies in hyperlipidaemic rabbits have demonstrated that superparamagnetic particles of iron oxide work by accumulating in atherosclerotic plaques with high levels of 
macrophages (since they are phagocytosed by these immune cells) causing MRI signal changes [114]. Liposome NPs used for imaging include nanoscale liposomal iohexol [115] and lipoproteins such as carboxyfluorescein-labeled apoE-derived incorporated into reconstituted high-density lipoprotein NP [116]. Lastly, to aid imaging of atherosclerotic plaques polymeric NPs are utilised (Figure 14) [117]. Such polymeric NPs have been used in hybrid PET/MR imaging of plaques since they can be radio-labelled through conjugation to zirconium-89 and thus allow diagnostic testing on therapeutic efficacy[117].

\section{Polymer Nanoparticle Preparations}

Various methods and techniques of polymer NP preparations exist. Preparation of PLLA-based magnetic NPs can be achieved through simple emulsion evaporation methods whereby an emulsified mixture containing both magnetic and polymer components is created and consequently evaporated through a rotative evaporator at $100 \mathrm{rpm}$ for about 15 minutes[118]. The formed NPs are then separated using a centrifuge, thereafter washed to eliminate excess materials and lastly the NP suspensions are placed into vials for freeze-drying[118].

Table 4. Nanoparticles used in diagnostic imaging.

\begin{tabular}{llll}
\hline Nanoparticle & Imaging modality & Imaging of & Ref \\
\hline $\begin{array}{l}\text { Nanoscale liposomal } \\
\text { iohexol }\end{array}$ & $\begin{array}{l}\text { Computed to- } \\
\text { mography }\end{array}$ & CVD & {$[113]$} \\
$\begin{array}{l}\text { Carboxyfluoresce- } \\
\text { in-labeled apoE-derived } \\
\text { incorporated into recon- } \\
\text { stituted high-density }\end{array}$ & MRI & CVD & {$[114]$} \\
$\begin{array}{l}\text { lipoprotein } \\
\begin{array}{l}\text { Cross-linked short chain } \\
\text { dextran polymer nanpar- }\end{array}\end{array}$ & PET/MRI & $\begin{array}{l}\text { Atheroscle- } \\
\text { rotic plaque }\end{array}$ & {$[115]$} \\
$\begin{array}{l}\text { Superparamagnetic iron } \\
\text { oxide }\end{array}$ & MRI & CVD, MI & {$[107$,} \\
$\begin{array}{l}\text { Oxazine fluorophore } \\
\text { coated tat-cross-linked } \\
\text { iron oxide }\end{array}$ & $\begin{array}{l}\text { Microscopic fluo- } \\
\text { rescence imaging } \\
\text { and fluorescence } \\
\text { reflectance imag- }\end{array}$ & MI & $108]$ \\
& $\begin{array}{l}\text { ing and } \\
\text { Off-resonance }\end{array}$ & MI & 1109, \\
$\begin{array}{l}\text { Monocrystalline iron } \\
\text { oxide }\end{array}$ & $\begin{array}{l}\text { muging and im- } \\
\text { munospecific MRI }\end{array}$ & & \\
\hline
\end{tabular}

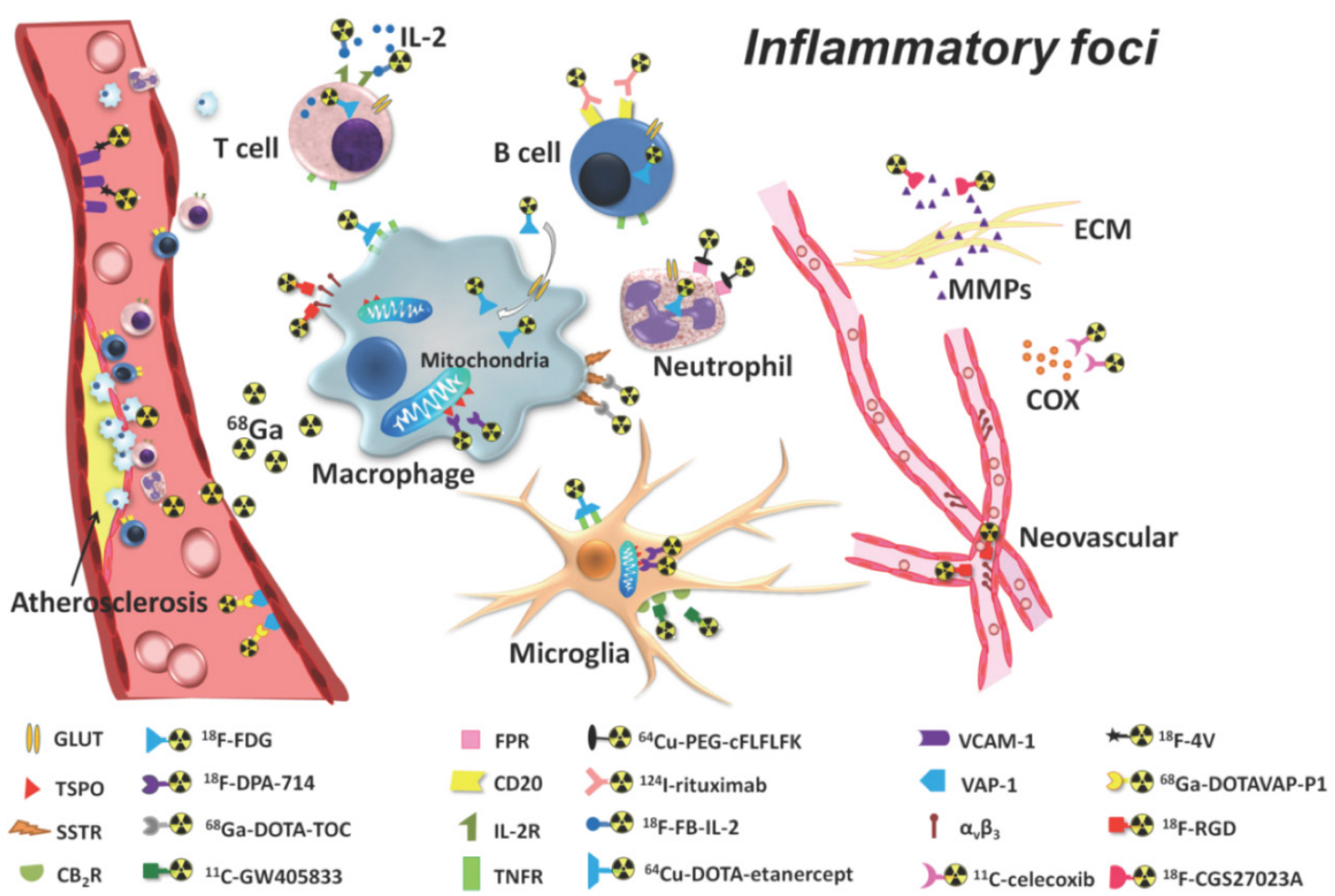

Figure 12. Detection of inflammatory foci using PET imaging tracers. The most widely used tracer in PET is considered to be $18 \mathrm{~F}-\mathrm{FDG}$ (2-deoxy-2-18F-fluoro-D-glucose). Copyright @) 2013 Ivyspring International Publisher. Reproduced with permission from [I0I]. 


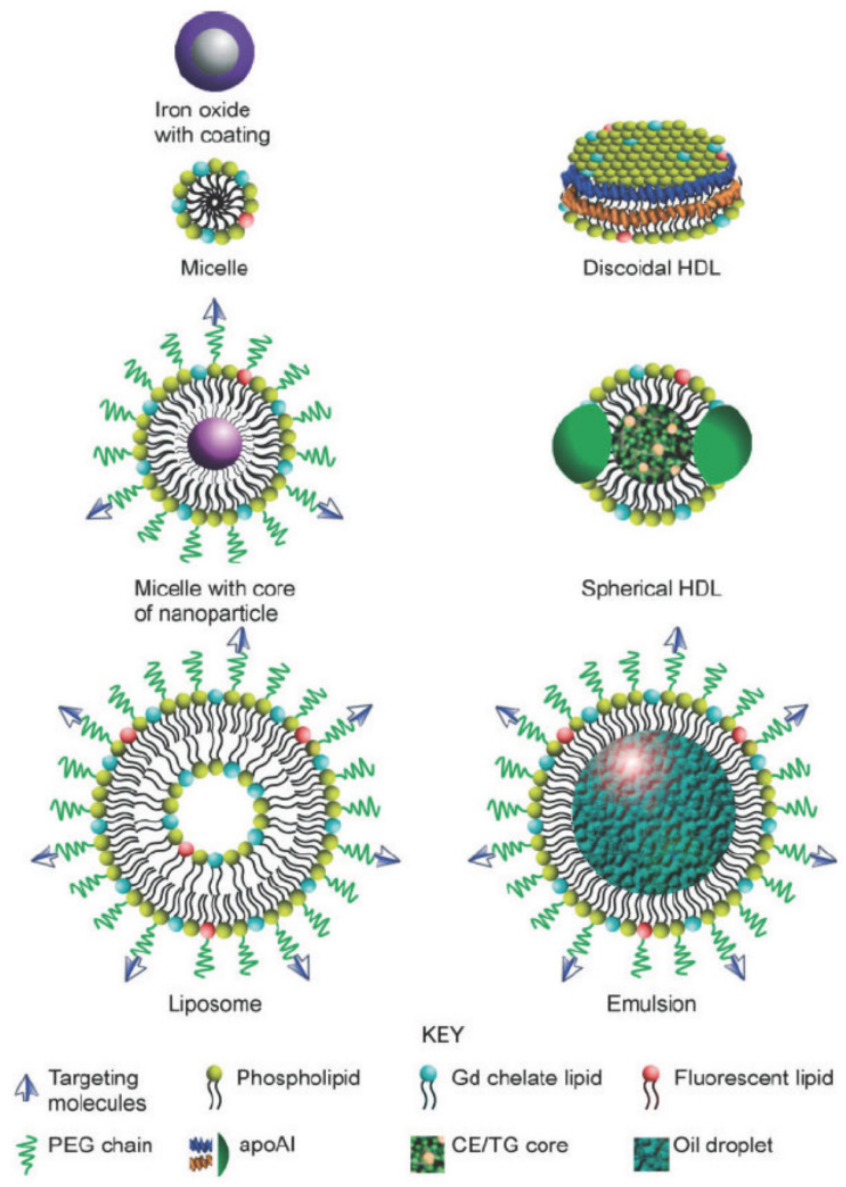

Figure 13. Diagram illustrating numerous nanoparticles that may be used for molecular imaging. PEG: polyethylene glycol. apoAl: apolipoprotein A I. Gd: gadolinium. CE: cholesteryl ester. TG: triglyceride. Copyright @ 2010 John Wiley \& Sons, Inc. Reproduced with permission from [34].

\section{A Hybrid Metallic/Polymeric Bioabsorb- able Stent?}

A dual metallic-polymeric fully bioabsorbable stent system, with a nano-theranostics at its core may revolutionise and transform current coronary stenting procedures. It is envisioned that such a scaffold may provide the mechanical and radial strength, high collapse pressure and low elastic recoil comparable to stainless steel stents yet the effective distribution and time controlled drug release platform which polymers can offer $[119,120]$. Furthermore, a nano-theranostic stent core may convey numerous clinical and medical benefits including drug delivery to specific sites thus reducing systemic adverse effects, protection of drug cargo which may allow for lower dose administration, improved ease of nanoparticle tracking and enhanced imaging of the intravascular site for patient monitoring post implantation[35, 71, 72].

The concept of a dual metallic-polymeric bioabsorbable stent has in fact recently been materialised into the FADES stent by Zorion Medical. This scaffold hybrid is composed of PLGA and a magnesium alloy
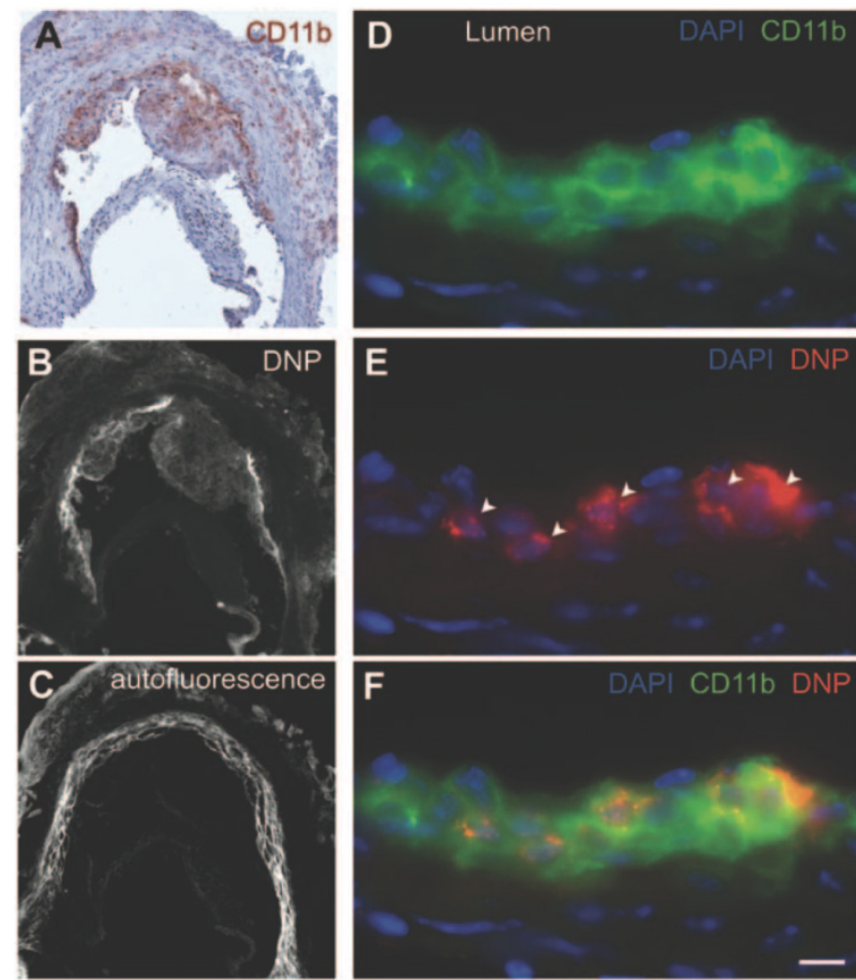

Figure 14. Dextran polymeric NPs present in various plaques. (A) Immunohistochemical stain visualising $\mathrm{CDIlb}+$ myeloid cells. (B) Fluorescence microscopy of A showing NP presence. (C) Autofluorescence image of B. (D) Immunofluorescence microscopy of CDI Ib under higher magnification. (E) Immunofluorescence microscopy of NPs (see arrows), same image as (D). (F) Images D and E combined where cells staining positive for CDI Ib show DNP presence inside. Scale bar $=20 \mu \mathrm{m}$. Copyright: (C) 2013 American Heart Association, Inc. Reproduced with permission from [1I5].

and preclinical trials have indicated complete stent resorption by 90 days as well as a low inflammatory markers present during this time period[36]. However, the possible disadvantage of a dual metallic-polymeric system lies in the possibility of greater stent strut thickness, which may convey a reduction in flexibility.

As for stent nano-theranostics, the paucity in the literature poses difficulty in ascertaining the current landscape in this application. Typically, nano-theranostics are delivered systemically; therefore an implant which encapsulates theranostics in its core, giving controlled drug release with enhanced imaging properties could be seen as a more streamlined approach to resolving current stenting obstacles, such as that of late stent thrombosis. In fact, there are porcine models demonstrating the nano-theranostic stent as a pioneering platform for delivery of NPs in targeting CVD[121]. In this study fluorescence markers of fluorescein-isothiocyanate (FITC) were imbedded into cationic PLGA NPs which were then deposited onto stainless steel stents and implanted into either left circumflex or left anterior descending coro- 
nary arteries of domestic male pigs[121]. Significant FITC fluorescence was observed in neointimal and medial layers of stented segments just 1 week after stent deployment, when compared to dip-coated stents consisting of thin layers of PLGA with FITC imbedded (Figure 15)[121]. Assessment of FITC-NP release kinetics was also carried out in vitro using human smooth muscle cells (SMCs) from the coronary artery indicating fast uptake and stable presence inside the cells for at least 24 hours (Figure 16)[121].

Given the complexities of developing a functional stent, it is envisioned that a paradigm shift towards a nano-theranostic bioabsorbable stent would be evolutionary rather than revolutionary. We envision that the initial step towards such a nano-thernostic stent platform would be the utilization of nanoparticles for localized drug delivery, followed by eventual nanoparticle imaging through nano-sized contrast agents. Possible theranostic candidates for bioabsorbable stent are shown in Table 5 .
Given the potential seen in PLLA as a material for bioabsorbable stents, we hypothesize that the next-generation nano-theranostic bioabsorbable stents could be made of PLLA dendrimers, with both drug (e.g. everolimus/paclitaxel) and diagnostic iron oxide payload. Indeed, Cao et al demonstrated that PLLA dendrimers encapsulating drug (specifically doxorubicin) is in fact feasible[122]. Moreover, Maraloiu et al has also developed a composite magnetic nanovector made of PLLA/rhenium nanospheres capable of carrying MRI contrast agents[123].

Table 5. Possible theranostic candidates for bioabsorbable stent.

\begin{tabular}{llll}
\hline Nanoparticles & Material & Therapeutic & Contrast agent \\
\hline Dendrimer & PLLA & paclitaxel/everolimus Iron oxide \\
Nanosphere & PLLA & paclitaxel/everolimus & $\begin{array}{l}\text { Iron oxide and } \\
\text { rhenium }\end{array}$ \\
\hline
\end{tabular}

A

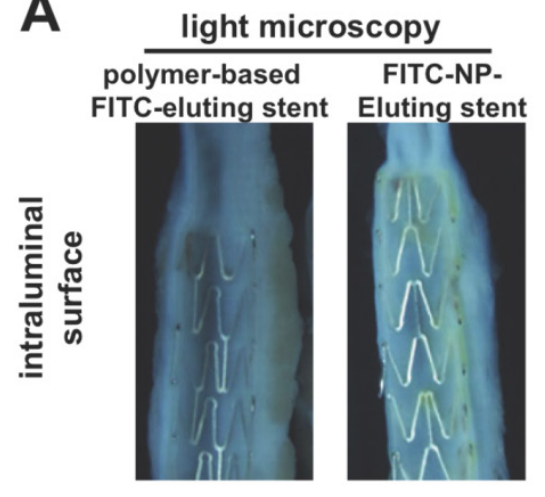

fluorescence microscopy

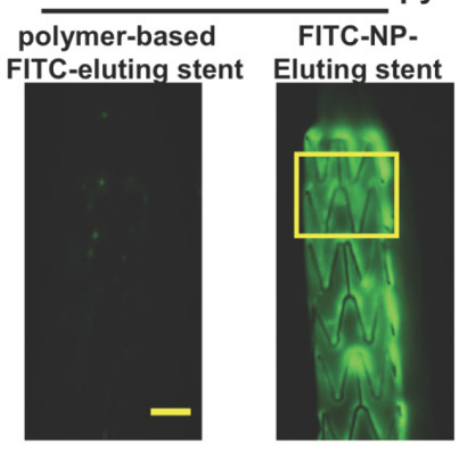

Figure 15. (A) Light and fluorescence microscopic pictures of stented intraluminal coronary artery segments of the FITC-NP-Eluting stent and dip-coated FITC stent (polymer-based FITC-eluting stent). Yellow scale bar $=1 \mathrm{~mm}$. (B) Expanded image of yellow box in A. Image B reveals distinct regions of fluorescence which indicate local uptake of FITC-NPs. (C) Cross-section fluorescence microscopic pictures of FITC-NP-Eluting stent and dip-coated FITC stent. *Stent strut region. Copyright (C) 2013 Elsevier B.V. Reproduced with permission from [118].

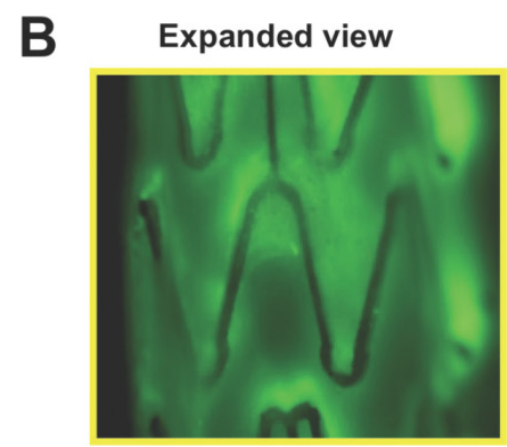

C

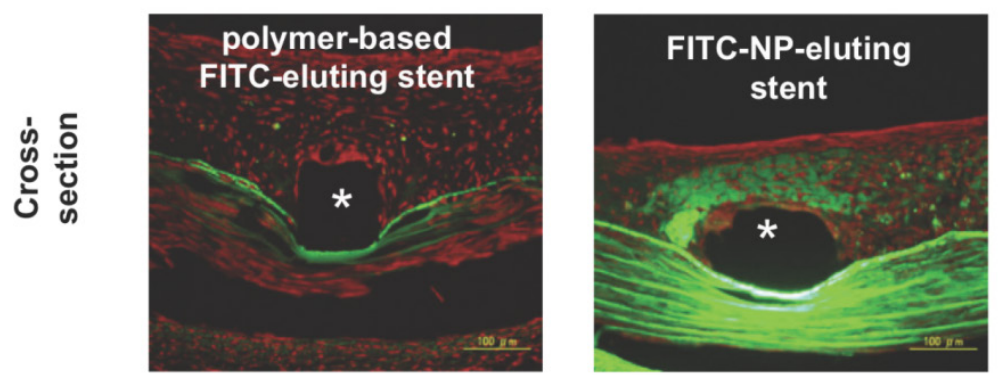



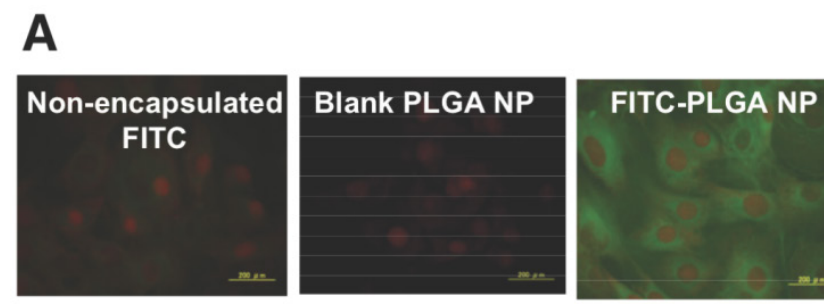

B

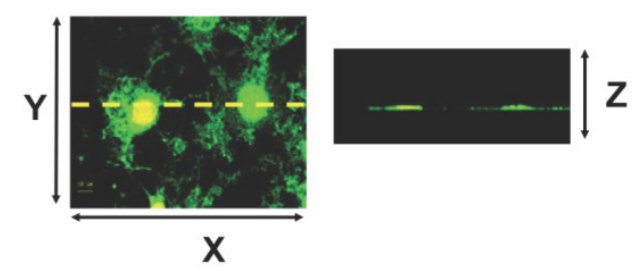

C Cellular uptake of nanoparticles (\%)

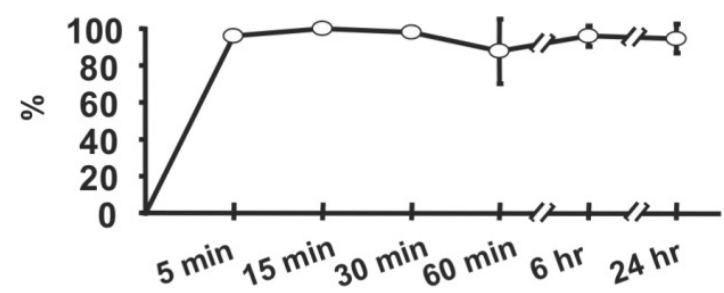

D

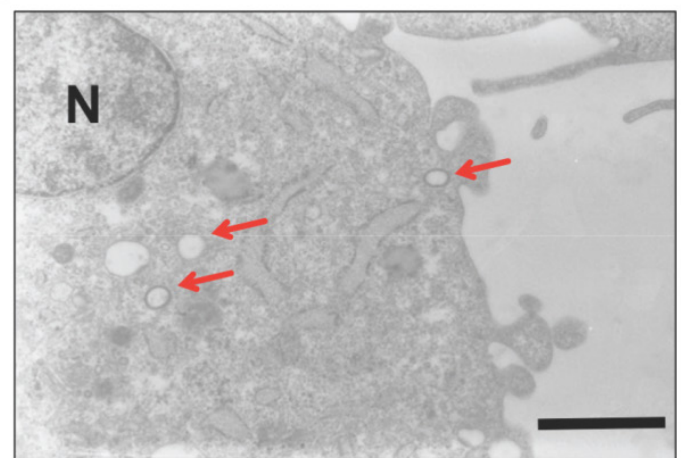

Figure 16. (A) In vitro human coronary artery SMCs visualised using fluorescence microscopy. Cells were incubated with non-encapsulated FITC, blank PLGA-NP and FITC-PLGA NP for one hour at a concentration of $0.1 \mathrm{mg} / \mathrm{ml}$. Green indicates FITC fluorescence and red indicates nuclei. FITC-PLGA NP demonstrates the most fluorescence. (B) In vitro human coronary artery SMCs incubated with FITC-NP at $0.1 \mathrm{mg} / \mathrm{ml}$ visualized using confocal fluorescence microscopy (left image showing $X Y$-axis and right image showing Z-axis of the left image). (C) Percentage of FITC-NP uptake of SMCs over a 24 hour period. (D) Cross-section of SMC visualized transmission electron microscopy. Arrows show FITC-NP uptake. $N=$ nucleus. Copyright $(\subset 2013$ Elsevier B.V. Reproduced with permission from [1 18].

\section{Conclusions and Future Directions}

Interventional cardiology has witnessed the development of many stent devices over the years. With coronary balloon angioplasty being superseded by BMS, it was soon established that such stents pose risks of neointimal hyperplasia. This paved the way for the revolutionary DES, such as those eluting paclitaxel or sirolimus and the demand for these stents increased significantly. However, such systems were soon presented with the issues of late-stent thrombosis and restenosis, the rates of which were proposed to be higher than that of BMS.

Since a stent is required to provide vessel patency and support for $6-12$ months, any time thereafter may be said to no longer provide any beneficial effects. Hence, the BDS system appears to be an intuitive approach to the next stenting revolution. This promising system aims to circumvent the concerns surrounding current stenting procedures of late-stent thrombosis and restenosis. Furthermore, benefits of BDS may include the facilitation of the return of vessel vasomotion, late luminal enlargement and late expansive remodelling because of a lack of permanence. Moreover, the use of BDS allows future interventions to be performed in vessel areas which have had stents in place.

Despite the promises offered by bioabsorbable stents, it is needless to say that many more RCTs comparing the efficacy of these devices against the more traditional stents of DES are still required. The Absorb BVS is the only BDS to obtain a CE mark status quo and is still in clinical trials, in comparison to numerous DES, which are routinely in clinical use presently. Thus, robust testing of BDS to industrial standards as well as presently used stenting methods are required to determine its viability in the scope of PCI.

It is proposed that a nano-theranostic bioabsorbable stent could consist of a PLLA polymer stent strut. This is the most frequently used BDS polymer available and has a degradation time of around 12 18 months. It is necessary that the stent upholds radial strength values similar to that of metallic stents and previous studies comparing BDS radial strengths to that of metallic ones have suggested this is entirely feasible. NPs such as liposomes, core shell nanoparticles, polymeric NPs or cationic lipoplexes embedded into stent struts are just a few of the array of NPs that may be used for controlled and targeted drug delivery for treating possible stent thrombosis and restenosis. In fact, experimental data on therapeutic liposome-based stents in vivo has demonstrated increased endothelialization[124]. The utilisation of iron oxide NPs in the stent core for precise and real-time monitoring of post-stent restenosis, assessment of stent endothelialization and thrombus formation is envisioned.

The use of NPs in vivo necessitates thorough toxicology studies to ascertain possible adverse effects and this field has been coined as nanotoxicology. The unique sizes of NPs have allowed them to cross cell membranes and have potential to access many tissues, which may introduce issues of cytotoxicity and inhi- 
bition of cell proliferation [125]. For example, it has been proposed that NPs may interfere which the immune system in ways that may cause immune suppression or stimulation with possible adverse immunotoxic effects as well as interactions with erythrocytes which may result in haemolysis [126, 127]. Thus, comprehensive assessments of chemical and biological interactions of tissues with NPs are critical in demonstrating their safety and viability as long-term medical devices, especially with regards to stenting technology.

In conclusion, given the likelihood that bioabsorbable stents would form the basis of stent designs in the future, more research into the use of nano-theranostics on bioabsorbable stent platforms would be of paramount importance and significance. The use of nano-theranostics in stenting would provide an incredibly valuable and streamlined single system, offering both therapeutic and diagnostic capabilities. Such capacities are manifold, including the delivery of therapeutic particles to specific sites thus keeping potential toxicity to a minimum, improved ease of tracking delivery in vivo by embedding imaging trackers, controlled rate of therapy release, and protection of the implanted therapy. Furthermore, nanocarriers may allow an increased therapeutic index as well as offer novel post-stent implantation imaging and diagnostic methods for atherosclerosis, restenosis and thrombosis. It is therefore hoped that a nano-theranostic stent may greatly enhance the clinical practice of percutaneous coronary intervention in the future.

\section{Abbreviations}

BAS: Bioabsorbable stent; BDS: Biodegradable stent; BMS: Bare metal stent; BP FL: Bisphosphonate fluorescent liposomes; BVS: Bioresorbable Vascular Scaffold; CE: Conformité Européenne; CER: Ceramide; CT: Computed tomography; DAPT: Dual antiplatelet therapy; DC: Dense calcium; DES: Drug eluting stent; EES: Everolimus eluting stent; FDA: Food and Drug Administration; FITC: Fluorescein-isothiocyanate; FL: Fluorescent liposomes; ID-MACE: Ischemia driven major adverse cardiovascular events; IVUS-VH: Intravascular ultrasound virtual histology; IVUS: Intravascular ultrasound; MACE: Major adverse cardiovascular events; MCUSA: Maximum circular unsupported cross sectional area; MPS: Metal platform stent; MRI: Magnetic resonance imaging; NC: Necrotic core; NPs: Nanoparticles; OCT: Optical coherence tomography; PCI: Percutaneous coronary intervention; PDLLA: Poly-D,L-lactide; PET: Positron emission tomography; PLLA: Poly-L-lactic acid; PTX: Paclitaxel; RCT: Randomized control trial; SBO: Side branch occlusion;
SPECT: Single photon emission computed tomography; ST: Stent thrombosis; US: Ultrasound

\section{Acknowledgements}

The authors would like to thank the Engineering and Physical Sciences Research Council (EPSRC) Industrial CASE for funding this research.

\section{Competing Interests}

The authors have declared that no competing interest exists.

\section{References}

1. Garg S, Serruys PW. Coronary stents: current status. J Am Coll Cardiol. 2010; 56: S1-42.

2. Rhee JW, Wu JC. Advances in nanotechnology for the management of coronary artery disease. Trends Cardiovasc Med. 2013; 23: 39-45.

3. Gruntzig A. Transluminal dilatation of coronary-artery stenosis. Lancet. 1978; 1: 263.

4. Sigwart U, Puel J, Mirkovitch V, et al. Intravascular stents to prevent occlusion and restenosis after transluminal angioplasty. N Engl J Med. 1987; 316: 701-706.

5. Serruys PW, Strauss BH, Beatt KJ, et al. Angiographic follow-up after placement of a self-expanding coronary-artery stent. N Engl J Med. 1991; 324: 13-17.

6. Brown DA, Lee EW, Loh CT, et al. A new wave in treatment of vascular occlusive disease: biodegradable stents-clinical experience and scientific principles. J Vasc Interv Radiol. 2009; 20: 315-324.

7. Serruys PW, Kutryk MJ, Ong AT. Coronary-artery stents. N Engl J Med. 2006; 354: 483-495.

8. Karas SP, Gravanis MB, Santoian EC, et al. Coronary intimal proliferation after balloon injury and stenting in swine: an animal model of restenosis. J Am Coll Cardiol. 1992; 20: 467-474.

9. Gordon PC, Gibson CM, Cohen DJ, et al. Mechanisms of restenosis and redilation within coronary stents--quantitative angiographic assessment. J Am Coll Cardiol. 1993; 21: 1166-1174.

10. Hoffmann R, Mintz GS, Dussaillant GR, et al. Patterns and mechanisms of in-stent restenosis. A serial intravascular ultrasound study. Circulation. 1996; 94: 1247-1254.

11. Curcio A, Torella D, Indolfi C. Mechanisms of smooth muscle cell proliferation and endothelial regeneration after vascular injury and stenting: approach to therapy. Circ J. 2011; 75: 1287-1296.

12. Holmes DR, Savage M, LaBlanche JM, et al. Results of Prevention of REStenosis with Tranilast and its Outcomes (PRESTO) trial. Circulation. 2002; 106: $1243-1250$

13. Stettler C, Wandel S, Allemann S, et al. Outcomes associated with drug-eluting and bare-metal stents: a collaborative network meta-analysis. Lancet. 2007; 370: 937-948.

14. Spaulding C, Daemen J, Boersma E, et al. A pooled analysis of data comparing sirolimus-eluting stents with bare-metal stents. N Engl J Med. 2007; 356: 989-997.

15. Stone GW, Moses JW, Ellis SG, et al. Safety and efficacy of sirolimus- and paclitaxel-eluting coronary stents. N Engl J Med. 2007; 356: 998-1008.

16. Maisel WH. Unanswered questions--drug-eluting stents and the risk of late thrombosis. N Engl J Med. 2007; 356: 981-984.

17. Grube E, Silber S, Hauptmann KE, et al. TAXUS I: six- and twelve-month results from a randomized, double-blind trial on a slow-release paclitaxel-eluting stent for de novo coronary lesions. Circulation. 2003; 107: 38-42.

18. Morice MC, Serruys PW, Sousa JE, et al. A randomized comparison of a sirolimus-eluting stent with a standard stent for coronary revascularization. N Engl J Med. 2002; 346: 1773-1780.

19. Pfisterer M, Brunner-La Rocca HP, Buser PT, et al. Late clinical events after clopidogrel discontinuation may limit the benefit of drug-eluting stents: an observational study of drug-eluting versus bare-metal stents. J Am Coll Cardiol. 2006; 48: 2584-2591.

20. Kedia G, Lee MS. Stent thrombosis with drug-eluting stents: a re-examination of the evidence. Catheter Cardiovasc Interv. 2007; 69: 782-789.

21. Tan A, Farhatnia Y, de Mel A, et al. Inception to actualization: next generation coronary stent coatings incorporating nanotechnology. J Biotechnol. 2013; 164: 151-170.

22. Stack RS, Califf RM, Phillips HR, et al. Interventional cardiac catheterization at Duke Medical Center. Am J Cardiol. 1988; 62: 3f-24f.

23. Saito S. New horizon of bioabsorbable stent. Catheter Cardiovasc Interv. 2005; 66: 595-596.

24. Colombo A, Karvouni E. Biodegradable stents: fulfilling the mission and stepping away. Circulation. 2000; 102: 371-373.

25. Erne P, Schier M, Resink TJ. The road to bioabsorbable stents: reaching clinical reality? Cardiovasc Intervent Radiol. 2006; 29: 11-16. 
26. Peuster $\mathrm{M}$, Wohlsein $\mathrm{P}$, Brugmann $\mathrm{M}$, et al. A novel approach to temporary stenting: degradable cardiovascular stents produced from corrodible metal-results 6-18 months after implantation into New Zealand white rabbits. Heart. 2001; 86: 563-569.

27. Garg S, Serruys PW. Coronary stents: looking forward. J Am Coll Cardiol. 2010; 56: S43-78.

28. Ormiston JA, Serruys PW. Bioabsorbable coronary stents. Circ Cardiovasc Interv. 2009; 2: 255-260

29. Inoue M, Sasaki M, Katada Y, et al. Poly-(L-lactic acid) and citric acid-crosslinked gelatin composite matrices as a drug-eluting stent coating material with endothelialization, antithrombogenic, and drug release properties. J Biomed Mater Res A. 2013; 101: 2049-2057.

30. Stone P, Lord JW. An experimental study of the thrombogenic properties of magnesium and magnesium-aluminum wire in the dog's aorta. Surgery. 1951 30: $987-993$

31. Jokerst JV, Gambhir SS. Molecular imaging with theranostic nanoparticles. Acc Chem Res. 2011; 44: 1050-1060.

32. Westedt U, Barbu-Tudoran L, Schaper AK, et al. Deposition of nanoparticles in the arterial vessel by porous balloon catheters: localization by confocal laser scanning microscopy and transmission electron microscopy. AAPS PharmSci. 2002; 4: E41.

33. Cabral H, Nishiyama N, Kataoka K. Supramolecular nanodevices: from design validation to theranostic nanomedicine. Acc Chem Res. 2011; 44: 999-1008.

34. Chen W, Cormode DP, Fayad ZA, et al. Nanoparticles as magnetic resonance imaging contrast agents for vascular and cardiac diseases. Wiley Interdiscip Rev Nanomed Nanobiotechnol. 2010; 3: 146-161.

35. Kolodgie FD, John M, Khurana C, et al. Sustained reduction of in-stent neointimal growth with the use of a novel systemic nanoparticle paclitaxel. Circulation. 2002; 106: 1195-1198.

36. Zhang $\mathrm{Y}$, Bourantas CV, Farooq V, et al. Bioresorbable scaffolds in the treatment of coronary artery disease. Med Devices (Auckl). 2013; 6: 37-48.

37. Waksman R, Pakala R, Baffour R, et al. Short-term effects of biocorrodible iron stents in porcine coronary arteries. J Interv Cardiol. 2008; 21: 15-20.

38. Hermawan H, Dube D, Mantovani D. Developments in metallic biodegradable stents. Acta Biomater. 2010; 6: 1693-1697.

39. Heublein B, Rohde R, Kaese V, et al. Biocorrosion of magnesium alloys: a new principle in cardiovascular implant technology? Heart. 2003; 89: 651-656.

40. Moravej M, Mantovani D. Biodegradable metals for cardiovascular stent application: interests and new opportunities. Int J Mol Sci. 2011; 12: 4250-4270.

41. Bosiers M, Peeters P, D'Archambeau O, et al. AMS INSIGHT-absorbable metal stent implantation for treatment of below-the-knee critical limb ischemia: 6-month analysis. Cardiovasc Intervent Radiol. 2009 32: 424-435.

42. Haude M, Erbel R, Erne P, et al. Safety and performance of the drug-eluting absorbable metal scaffold (DREAMS) in patients with de-novo coronary lesions: 12 month results of the prospective, multicentre, first-in-man BIOSOLVE-I trial. Lancet. 2013; 381: 836-844.

43. van der Giessen WJ, Lincoff AM, Schwartz RS, et al. Marked inflammatory sequelae to implantation of biodegradable and nonbiodegradable polymers in porcine coronary arteries. Circulation. 1996; 94: 1690-1697.

44. Tamai H, Igaki K, Kyo E, et al. Initial and 6-month results of biodegradable poly-l-lactic acid coronary stents in humans. Circulation. 2000; 102: 399-404.

45. Tsuji T, Tamai H, Igaki K, et al. Biodegradable Polymeric Stents. Curr Interv Cardiol Rep. 2001; 3: 10-17.

46. Nishio S, Kosuga K, Igaki K, et al. Long-Term (>10 Years) clinical outcomes of first-in-human biodegradable poly-l-lactic acid coronary stents: Igaki-Tamai stents. Circulation. 2012; 125: 2343-2353.

47. Serruys PW, Ormiston JA, Onuma Y, et al. A bioabsorbable everolimus-eluting coronary stent system (ABSORB): 2-year outcomes and results from multiple imaging methods. Lancet. 2009; 373: 897-910.

48. Ormiston JA, Webster MW, Armstrong G. First-in-human implantation of a fully bioabsorbable drug-eluting stent: the BVS poly-L-lactic acid everolimus-eluting coronary stent. Catheter Cardiovasc Interv. 2007; 69: 128-131.

49. Oberhauser JP, Hossainy S, Rapoza RJ. Design principles and performance of bioresorbable polymeric vascular scaffolds. Eurointervention. 2009; 5 (Suppl F): F15-22

50. Ulery BD, Nair LS, Laurencin CT. Biomedical applications of biodegradable polymers. J Polym Sci B. 2011; 49: 832-864.

51. Pitt CG, Gratzl MM, Kimmel GL, et al. Aliphatic polyesters II. The degradation of poly (DL-lactide), poly (epsilon-caprolactone), and their copolymers in vivo. Biomaterials. $1981 ; 2: 215-220$.

52. Weir NA, Buchanan FJ, Orr JF, et al. Degradation of poly-L-lactide. Part 1: in vitro and in vivo physiological temperature degradation. Proc Inst Mech Eng H. 2004; 218:307-319.

53. Weir NA, Buchanan FJ, Orr JF, et al. Degradation of poly-L-lactide. Part 2: increased temperature accelerated degradation. Proc Inst Mech Eng H. 2004; 218: 321-330.

54. Jukema JW, Ahmed TA, Verschuren JJ, et al. Restenosis after PCI. Part 2: prevention and therapy. Nat Rev Cardiol. 2012; 9: 79-90.

55. Onuma Y, Serruys PW, Ormiston JA, et al. Three-year results of clinical follow-up after a bioresorbable everolimus-eluting scaffold in patients with de novo coronary artery disease: the ABSORB trial. Eurointervention. 2010; 6: 447-453.

56. Brugaletta S, Garcia-Garcia HM, Diletti R, et al. Comparison between the first and second generation bioresorbable vascular scaffolds: a six month virtual histology study. Eurointervention. 2011; 6: 1110-1116.
57. Gomez-Lara J, Brugaletta S, Diletti R, et al. A comparative assessment by optical coherence tomography of the performance of the first and second generation of the everolimus-eluting bioresorbable vascular scaffolds. Eur Heart J. 2011; 32: 294-304.

58. Gomez-Lara J, Brugaletta S, Farooq V, et al. Head-to-head comparison of the neointimal response between metallic and bioresorbable everolimus-eluting scaffolds using optical coherence tomography. JACC Cardiovasc Interv. 2011; 4: $1271-1280$

59. Gomez-Lara J, Garcia-Garcia HM, Onuma Y, et al. A comparison of the conformability of everolimus-eluting bioresorbable vascular scaffolds to metal platform coronary stents. JACC Cardiovasc Interv. 2010; 3: 1190-1198.

60. Okamura T, Garg S, Gutierrez-Chico JL, et al. In vivo evaluation of stent strut distribution patterns in the bioabsorbable everolimus-eluting device: an OCT ad hoc analysis of the revision 1.0 and revision 1.1 stent design in the ABSORB clinical trial. Eurointervention. 2010; 5: 932-938.

61. Onuma Y, Serruys PW, Gomez J, et al. Comparison of in vivo acute stent recoil between the bioresorbable everolimus-eluting coronary scaffolds (revision 1.0 and 1.1) and the metallic everolimus-eluting stent. Catheter Cardiovasc Interv. 2011; 78: 3-12

62. Tanimoto S, Serruys PW, Thuesen L, et al. Comparison of in vivo acute stent recoil between the bioabsorbable everolimus-eluting coronary stent and the everolimus-eluting cobalt chromium coronary stent: insights from the ABSORB and SPIRIT trials. Cathether Cardiovasc Interv. 2007; 70: 515-523.

63. Brugaletta S, Radu MD, Garcia-Garcia HM, et al. Circumferential evaluation of the neointima by optical coherence tomography after ABSORB bioresorbable vascular scaffold implantation: can the scaffold cap the plaque? Atherosclerosis. 2012; 221: 106-112.

64. Diletti R, Farooq V, Girasis C, et al. Clinical and intravascular imaging outcomes at 1 and 2 years after implantation of absorb everolimus eluting bioresorbable vascular scaffolds in small vessels. Late lumen enlargement: does bioresorption matter with small vessel size? Insight from the ABSORB cohort B trial. Heart. 2013; 99: 98-105.

65. Dudek D, Onuma Y, Ormiston JA, et al. Four-year clinical follow-up of the ABSORB everolimus-eluting bioresorbable vascular scaffold in patients with de novo coronary artery disease: the ABSORB trial. Eurointervention. 2012; 7: 1060-1061.

66. Muramatsu T, Onuma Y, Garcia-Garcia HM, et al. Incidence and short-term clinical outcomes of small side branch occlusion after implantation of an everolimus-eluting bioresorbable vascular scaffold: an interim report of 435 patients in the ABSORB-EXTEND single-arm trial in comparison with an everolimus-eluting metallic stent in the SPIRIT first and II trials. JACC Cardiovasc Interv. 2013; 6: 247-257.

67. Ormiston JA, Serruys PW, Regar E, et al. A bioabsorbable everolimus-eluting coronary stent system for patients with single de-novo coronary artery lesions (ABSORB): a prospective open-label trial. Lancet. 2008; 371: 899-907.

68. Sarno G, Bruining N, Onuma Y, et al. Morphological and functional evaluation of the bioresorption of the bioresorbable everolimus-eluting vascular scaffold using IVUS, echogenicity and vasomotion testing at two year follow-up: a patient level insight into the ABSORB A clinical trial. Int J Cardiovasc Imaging. 2012; 28: 51-58

69. Serruys PW, Onuma Y, Dudek D, et al. Evaluation of the second generation of a bioresorbable everolimus-eluting vascular scaffold for the treatment of de novo coronary artery stenosis: 12 -month clinical and imaging outcomes. J Am Coll Cardiol. 2011; 58: 1578-1588.

70. Ding $\mathrm{H}, \mathrm{Wu}$ F. Image guided biodistribution and pharmacokinetic studies of theranostics. Theranostics. 2012; 2: 1040-1053.

71. Nystrom AM, Wooley KL. The importance of chemistry in creating well-defined nanoscopic embedded therapeutics: devices capable of the dual functions of imaging and therapy. Acc Chem Res. 2011; 44: 969-978.

72. Binsalamah ZM, Paul A, Prakash S, et al. Nanomedicine in cardiovascular therapy: recent advancements. Expert Rev Cardiovasc Ther. 2012; 10: 805-815.

73. Huang G, Zhang C, Li S, et al. A Novel Strategy for Surface Modification of Superparamagnetic Iron Oxide Nanoparticles for Lung Cancer Imaging. J Mater Chem. 2009; 19: 6367-6372.

74. Lu J, Liong M, Zink JI, et al. Mesoporous silica nanoparticles as a delivery system for hydrophobic anticancer drugs. Small. 2007; 3: 1341-1346.

75. Thomas CR, Ferris DP, Lee JH, et al. Noninvasive remote-controlled release of drug molecules in vitro using magnetic actuation of mechanized nanoparticles. J Am Chem Soc. 2010; 132: 10623-10625.

76. Duncan R. The dawning era of polymer therapeutics. Nat Rev Drug Discov. 2003; 2: 347-360.

77. Ferrari M. Cancer nanotechnology: opportunities and challenges. Nat Rev Cancer. 2005; 5: 161-171.

78. Davis ME, Chen ZG, Shin DM. Nanoparticle therapeutics: an emerging treatment modality for cancer. Nat Rev Drug Discov. 2008; 7: 771-782.

79. Kataoka K, Harada A, Nagasaki Y. Block copolymer micelles for drug delivery: design, characterization and biological significance. Adv Drug Deliv Rev. 2001; 47: 113-131.

80. Nishiyama N, Kataoka K. Current state, achievements, and future prospects of polymeric micelles as nanocarriers for drug and gene delivery. Pharmacol Ther. 2006; 112: 630-648.

81. Northfelt DW, Dezube BJ, Thommes JA, et al. Pegylated-liposomal doxorubicin versus doxorubicin, bleomycin, and vincristine in the treatment of AIDS-related Kaposi's sarcoma: results of a randomized phase III clinical trial. J Clin Oncol. 1998; 16: 2445-2451. 
82. Gordon AN, Tonda M, Sun S, et al. Long-term survival advantage for women treated with pegylated liposomal doxorubicin compared with topotecan in a phase 3 randomized study of recurrent and refractory epithelial ovarian cancer. Gynecol Oncol. 2004; 95: 1-8.

83. O'Brien ME, Wigler N, Inbar M, et al. Reduced cardiotoxicity and comparable efficacy in a phase III trial of pegylated liposomal doxorubicin $\mathrm{HCl}$ (CAELYX/Doxil) versus conventional doxorubicin for first-line treatment of metastatic breast cancer. Ann Oncol. 2004; 15: 440-449.

84. Gradishar WJ, Tjulandin S, Davidson N, et al. Phase III trial of nanoparticle albumin-bound paclitaxel compared with polyethylated castor oil-based paclitaxel in women with breast cancer. J Clin Oncol. 2005; 23: 7794-7803.

85. Chacko AM, Hood ED, Zern BJ, et al. Targeted Nanocarriers for Imaging and Therapy of Vascular Inflammation. Curr Opin Colloid Interface Sci. 2011; 16: 215-227.

86. Masuda S, Nakano K, Funakoshi K, et al. Imatinib mesylate-incorporated nanoparticle-eluting stent attenuates in-stent neointimal formation in porcine coronary arteries. J Atheroscler Thromb. 2011; 18: 1043-1053.

87. Yang J, Zeng $Y$, Zhang $C$, et al. The prevention of restenosis in vivo with a VEGF gene and paclitaxel co-eluting stent. Biomaterials. 2013; 34: 1635-1643.

88. Jiang $\mathrm{H}$, Zhang $\mathrm{T}$, Sun $\mathrm{X}$. Vascular endothelial growth factor gene delivery by magnetic DNA nanospheres ameliorates limb ischemia in rabbits. J Surg Res. 2005; 126: 48-54.

89. Bhargava B, Reddy NK, Karthikeyan G, et al. A novel paclitaxel-eluting porous carbon-carbon nanoparticle coated, nonpolymeric cobalt-chromium stent: evaluation in a porcine model. Catheter Cardiovasc Interv. 2006; 67: 698-702.

90. Uwatoku T, Shimokawa H, Abe K, et al. Application of nanoparticle technology for the prevention of restenosis after balloon injury in rats. Circ Res. 2003; 92: e62-69.

91. Banai S, Chorny M, Gertz SD, et al. Locally delivered nanoencapsulated tyrphostin (AGL-2043) reduces neointima formation in balloon-injured rat carotid and stented porcine coronary arteries. Biomaterials. 2005; 26: 451-461.

92. Golub JS, Kim YT, Duvall CL, et al. Sustained VEGF delivery via PLGA nanoparticles promotes vascular growth. Am J Physiol Heart Circ Physiol. 2010; 298: H1959-1965.

93. Oda S, Nagahama R, Nakano K, et al. Nanoparticle-mediated endothelial cell-selective delivery of pitavastatin induces functional collateral arteries (therapeutic arteriogenesis) in a rabbit model of chronic hind limb ischemia. J Vasc Surg. 2010; 52: 412-420.

94. Deshpande D, Devalapally H, Amiji M. Enhancement in anti-proliferative effects of paclitaxel in aortic smooth muscle cells upon co-administration with ceramide using biodegradable polymeric nanoparticles. Pharm Res. 2008; 25: 1936-1947.

95. Sawa Y, Morishita R, Suzuki K, et al. A novel strategy for myocardial protection using in vivo transfection of cis element 'decoy' against NFkappaB binding site: evidence for a role of NFkappaB in ischemia-reperfusion injury. Circulation. 1997; 96: 280-284.

96. Suzuki K, Sawa $Y$, Kaneda $Y$, et al. In vivo gene transfection with heat shock protein 70 enhances myocardial tolerance to ischemia-reperfusion injury in rat. J Clin Invest. 1997; 99: 1645-1650.

97. Danenberg HD, Fishbein I, Gao J, et al. Macrophage depletion by clodronate-containing liposomes reduces neointimal formation after balloon injury in rats and rabbits. Circulation. 2002; 106: 599-605.

98. Gutman D, Golomb G. Liposomal alendronate for the treatment of restenosis. J Control Release. 2012; 161: 619-627.

99. Pelisek J, Fuchs A, Engelmann MG, et al. Vascular endothelial growth factor response in porcine coronary and peripheral arteries using nonsurgical occlusion model, local delivery, and liposome-mediated gene transfer. Endothelium. 2003; 10: 247-255.

100. Lindner JR. Molecular imaging of cardiovascular disease with contrast-enhanced ultrasonography. Nat Rev Cardiol. 2009; 6: 475-481.

101. van der Hoeven BL, Schalij MJ, Delgado V. Multimodality imaging in interventional cardiology. Nat Rev Cardiol. 2012; 9: 333-346.

102. Wu C, Li F, Niu G, et al. PET imaging of inflammation biomarkers. Theranostics. 2013; 3: 448-466

103. Lammers T, Kiessling F, Hennink WE, et al. Nanotheranostics and image-guided drug delivery: current concepts and future directions. Mol Pharm. 2010; 7: 1899-1912

104. Chen KJ, Wolahan SM, Wang H, et al. A small MRI contrast agent library of gadolinium(III)-encapsulated supramolecular nanoparticles for improved relaxivity and sensitivity. Biomaterials. 2011; 32: 2160-2165.

105. Straathof R, Strijkers GJ, Nicolay K. Target-specific paramagnetic and superparamagnetic micelles for molecular MR imaging. Methods Mol Biol. 2011; 771: 691-715.

106. Ben-Dor I, Mahmoudi M, Pichard AD, et al. Optical coherence tomography: a new imaging modality for plaque characterization and stent implantation. J Interv Cardiol. 2011; 24: 184-192.

107. Yonetsu T, Bouma BE, Kato K, et al. Optical coherence tomography- 15 years in cardiology. Circ J. 2013; 77: 1933-1940.

108. Kooi ME, Cappendijk VC, Cleutjens KB, et al. Accumulation of ultrasmall superparamagnetic particles of iron oxide in human atherosclerotic plaques can be detected by in vivo magnetic resonance imaging. Circulation. 2003; 107: 2453-2458.
109. Chapon C, Franconi F, Lemaire L, et al. High field magnetic resonance imaging evaluation of superparamagnetic iron oxide nanoparticles in a permanent rat myocardial infarction. Invest Radiol. 2003; 38: 141-146.

110. Panizzi $\mathrm{P}$, Nahrendorf $\mathrm{M}$, Wildgruber $\mathrm{M}$, et al. Oxazine conjugated nanoparticle detects in vivo hypochlorous acid and peroxynitrite generation. J Am Chem Soc. 2009; 131: 15739-15744

111. Koch AM, Reynolds F, Kircher MF, et al. Uptake and metabolism of a dual fluorochrome Tat-nanoparticle in HeLa cells. Bioconjug Chem. 2003; 14: 1115-1121.

112. Farrar CT, Dai G, Novikov M, et al. Impact of field strength and iron oxide nanoparticle concentration on the linearity and diagnostic accuracy of off-resonance imaging. NMR Biomed. 2008; 21: 453-463.

113. Weissleder R, Lee AS, Khaw BA, et al. Antimyosin-labeled monocrystalline iron oxide allows detection of myocardial infarct: MR antibody imaging. Radiology. 1992; 182: 381-385.

114. Ruehm SG, Corot C, Vogt P, et al. Magnetic resonance imaging of atherosclerotic plaque with ultrasmall superparamagnetic particles of iron oxide in hyperlipidemic rabbits. Circulation. 2001; 103: 415-22.

115. Kao CY, Hoffman EA, Beck KC, et al. Long-residence-time nano-scale liposomal iohexol for X-ray-based blood pool imaging. Acad Radiol. 2003; 10: 475-83.

116. Chen W, Vucic E, Leupold E, et al. Incorporation of an apoE-derived lipopeptide in high-density lipoprotein MRI contrast agents for enhanced imaging of macrophages in atherosclerosis. Contrast Media Mol Imaging. 2008; 3: 233-42.

117. Majmudar MD, Yoo J, Keliher EJ, et al. Polymeric nanoparticle PET/MR imaging allows macrophage detection in atherosclerotic plaques. Circ Res. 2013; 112: 755-761.

118. Hamoudeh M, Al Faraj A, Canet-Soulas E, et al. Elaboration of PLLA-based superparamagnetic nanoparticles: characterization, magnetic behaviour study and in vitro relaxivity evaluation. Int J Pharm. 2007; 338: 248-57.

119. Erbel R, Di Mario C, Bartunek J, et al. Temporary scaffolding of coronary arteries with bioabsorbable magnesium stents: a prospective, non-randomised multicentre trial. Lancet. 2007; 369: 1869-75.

120. Uhrich KE, Cannizzaro SM, Langer RS, et al. Polymeric Systems for Controlled Drug Release. Chem Rev. 1999; 99: 3181-98.

121. Nakano K, Egashira K, Masuda S, et al. Formulation of nanoparticle-eluting stents by a cationic electrodeposition coating technology: efficient nano-drug delivery via bioabsorbable polymeric nanoparticle-eluting stents in porcine coronary arteries. JACC Cardiovasc Interv. 2009; 2: 277-83.

122. Cao W, Zhou J, Mann A, et al. Folate-functionalized unimolecular micelles based on a degradable amphiphilic dendrimer-like star polymer for cancer cell-targeted drug delivery. Biomacromolecules. 2011; 12: 2697-707.

123. Maraloiu VA, Hamoudeh M, Fessi H, et al. Study of magnetic nanovectors by Wet-STEM, a new ESEM mode in transmission. J Colloid Interface Sci. 2010; 352: 386-92.

124. Sharif F, Hynes SO, McCullagh KJ, et al. Gene-eluting stents: non-viral, liposome-based gene delivery of eNOS to the blood vessel wall in vivo results in enhanced endothelialization but does not reduce restenosis in a hypercholesterolemic model. Gene Ther. 2012; 19: 321-8.

125. Magrez A, Kasas S, Salicio V, et al. Cellular toxicity of carbon-based nanomaterials. Nano Lett. 2006; 6: 1121-5.

126. Ghosh M, Chakraborty A, Mukherjee A. Cytotoxic, genotoxic and the hemolytic effect of titanium dioxide (TiO2 ) nanoparticles on human erythrocyte and lymphocyte cells in vitro. J Appl Toxicol. 2013; 33: 1097-110.

127.Yu T, Malugin A, Ghandehari H. Impact of silica nanoparticle design on cellular toxicity and hemolytic activity. ACS Nano. 2011; 5: 5717-28.

\section{Author Biography}

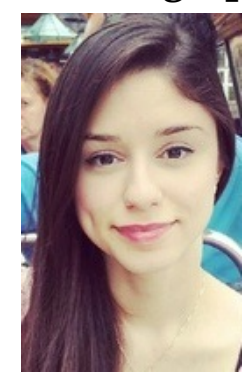
medical student at University College London (UCL), and is currently pursuing her BSc in Surgical Sciences at the UCL Division of Surgery \& Interventional Science, working on biomaterials and nanotechnology. 


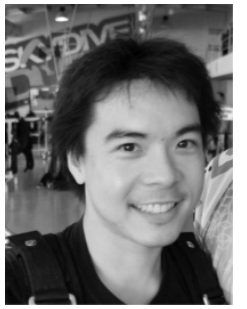

Aaron Tan, BSc, MPhil, is a medical student at UCL in the dual-degree clinician-scientist MBBS-PhD programme. He obtained his BSc in Surgical Sciences at UCL, and is currently in his final $\mathrm{PhD}$ year under the supervision of Prof. Alexander M. Seifalian at the UCL Division of Surgery \& Interventional Science, researching on bioengineered coronary stents utilizing nanotechnology.

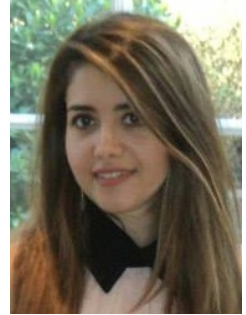

Dr. Yasmin Farhatnia, BSc, MSc, $\mathrm{PhD}$, is currently a postdoctoral researcher at the UCL Division of Surgery \& Interventional Science, working on the development of next-generation coronary stent platforms for both adult and paediatric applications using advanced nanocomposite polymers. She obtained her BSc from Queen Mary University of London (QMUL), and both her MSc and PhD from UCL.

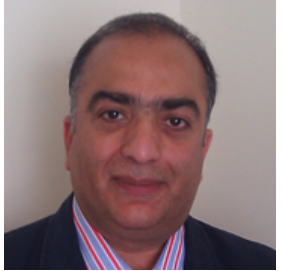

Dr. Mohammad S. Alavijeh, PhD, is the Managing Director of Pharmidex Pharmaceutical Services Limited, which has industrial and academic collaborations with the Engineering and Physical Research Council (EPSRC) in training the next generation clinician-scientists. His research and expertise is in drug discovery, cardiovascular disease, cancer, inflammation, and pharmacokinetics. Prior to founding Pharmidex, he was head of drug metabolism, pharmacokinetic and pharmacodynamics (DMPK/PD) at Vernalis Research, and also DMPK team leader at Aventis Pharma (Sanofi). He obtained his PhD from UCL, and previously worked at the world-renowned Institute of Neurology at Queen Square.

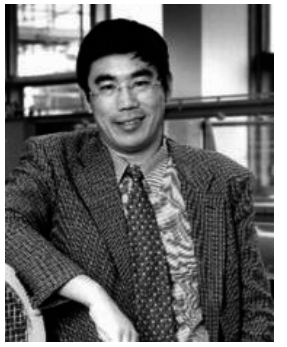

Prof. Zhanfeng Cui, PhD, DSc, FIChemE, FREng, is the Donald Pollock Professor of Chemical Engineering at the University of Oxford, and a Professorial Fellow of Hertford College, Oxford. He is also director of the Oxford Centre for Tissue Engineering and Bioprocessing at the Department of Engineering Science at Oxford University. He works on the forefront of 3D perfusion of bioreactors, and has founded a spin-off company, Zyoxel, to commercialize TissueFlex®, a microbioreactor for 3D perfused cell culture, and LiverChip ${ }^{\mathrm{TM}}$, a lab-on-a-chip microfluidic device that mimics biological organs. He obtained his BSc, MSc, and PhD degrees from China, and his MA and DSc from Oxford University. He is a Fellow of the Institution of Chemical Engineers, and was recently elected as a Fellow of the Royal Academy of Engineering.

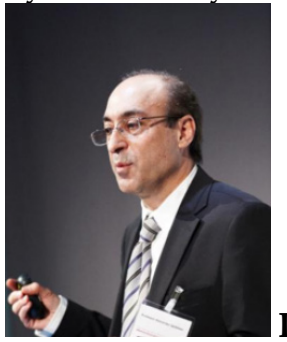
MSc, PhD, FIoN, FSB, is Professor of Nanotechnology and Regenerative Medicine at UCL, and director of the Centre for Nanotechnology and Regenerative Medicine at the UCL Division of Surgery and Interventional Science. He has achieved top prizes and accolades from multiple panels including Medical Futures Innovation, UK Trade \& Investment (UKTI), and European Life Science. His research interests are in the area of nanoscience and nanotechnology for medical applications, many of which have resulted in commercialization and/or translation into first-in-man studies. He obtained his BSc from Kings College London, MSc from University of London, and PhD from UCL. He is a Fellow of the Institute of Nanotechnology, and a Fellow of the Society of Biology. His group recently developed the world's first bioartificial trachea, which was successfully transplanted into a patient in 2011 . 